Technical Report

October 1997

\title{
Feasibility of Wireless Data Transmission on Ships
}

\author{
by
}

David S. Hosom

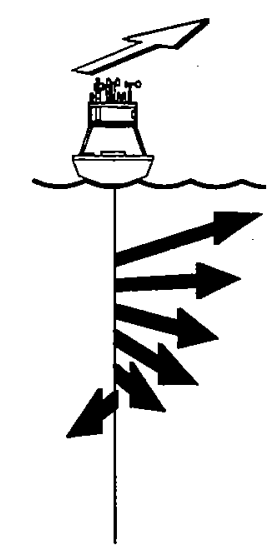

Upper Ocean Processes Group Woods Hole Oceanographic Institution Woods Hole, Massachusetts 02543

UOP Technical Report 97-04 
WHOI-97-14

UOP-97-04

\title{
Feasibility of Wireless Data Transmission on Ships
}

\author{
by
}

David S. Hosom

\begin{abstract}
Woods Hole Oceanographic Institution
Woods Hole, Massachusetts 02543
\end{abstract}

October 1997

\section{Technical Report}

Funding was provided by the National Science Foundation through Grant No. OCE96-32461.

\begin{abstract}
Reproduction in whole or in part is permitted for any purpose of the United States Government. This report should be cited as Woods Hole Oceanog. Inst. Tech. Rept., WHOI-97-14.
\end{abstract}

Approved for public release; distribution unlimited.

\section{Approved for Distribution:}

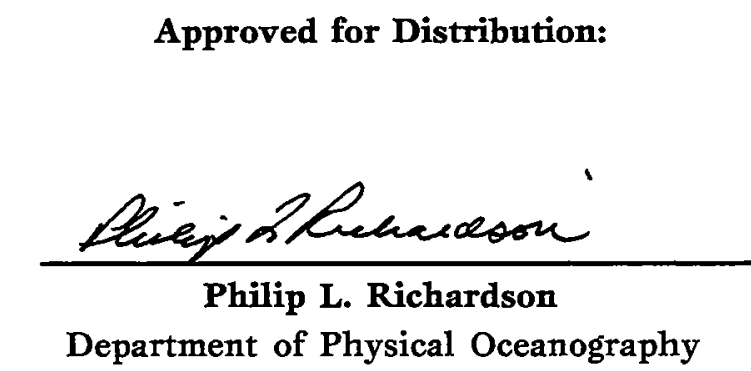




\begin{abstract}
This report will present the results of an investigation into the feasibility of several modes of wireless data transmission including: (1) radio frequency modems, (2) acoustic modems (using the ship's steel hull for a path with a "HullPhone"), (3) power line systems, such as X-10 units, and (4) possible power line utilization of telephone modems.

There is a need for wireless data transmission on both Voluntary Observing Ships (VOS) and research ships for short-term installations. The availability of cables from remote areas on these ships is usually not good, and restrictions on installing cables prevent some useful measurements from being made. A case in point is the real time availability of measurements of sea surface temperature (SST) from VOS by sensors mounted inside the hull. Instruments for measuring SST are installed in sealed compartments that are near the waterline of the ship and often four decks below the main deck. Other applications include transmission of data from automated XBT launchers located on the aft deck to the science area and transmission of data from a cluster of meteorological instruments located at the bow of the ship to the bridge for interface to Service Argos or Inmarsat satellite links.
\end{abstract}

Surveys of existing equipment have been made. Typical equipment has been purchased and was tested in a ship environment, including the "HullPhone". The results of these tests are presented. Suggestions for system configurations to meet the applications noted above are made with note of the product development required. 


\section{TABLE OF CONTENTS}

Abstract

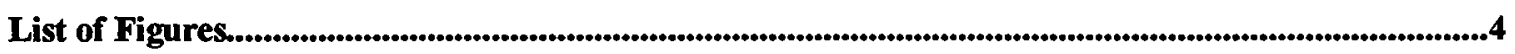

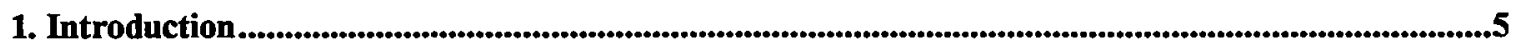

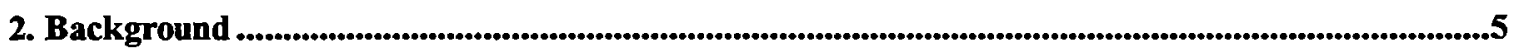

A. The need for wireless data transmission ......................................................................................5

B. State of the art of UOP-VOS...............................................................................................................

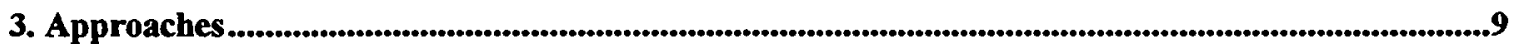

A. Radio frequency modems............................................................................................................10

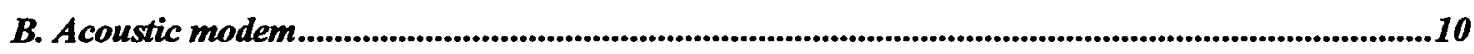

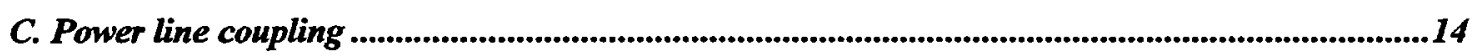

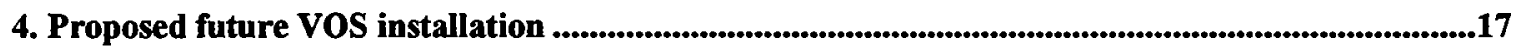

5. Summary................................................................................................................................................................17

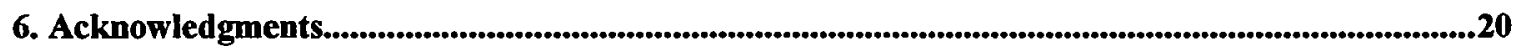

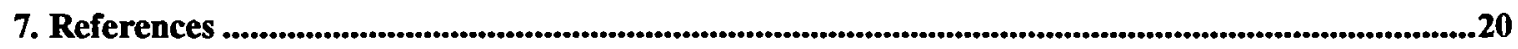

Appendix 1: List of radio frequency modems...................................................................................................21

Appendix 2: Data sheets

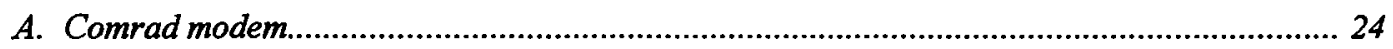

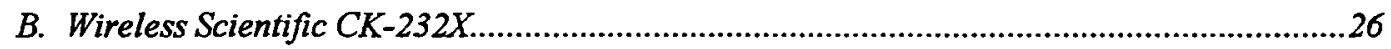

C. Wireless Scientific CK-232 2............................................................................................. 28

Appendix 3: Technical information

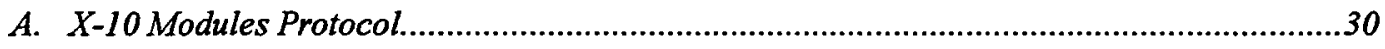

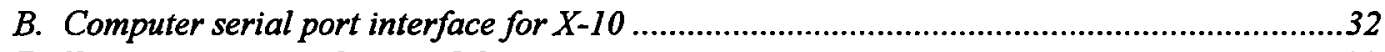

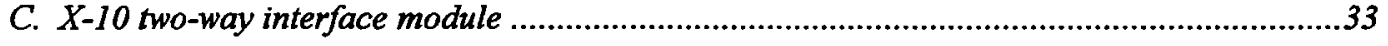




\section{List of Figures}

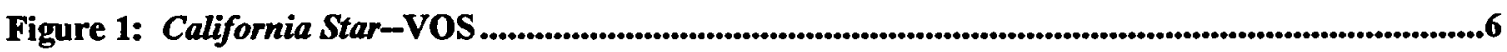

Figure 2: SST modules in hold of California Star .....................................................................................7

Figure 3: IMET on bow mast of RV Oceanus.............................................................................................8

Figure 4: Radio frequency modem-Bridge RS232 unit................................................................11

Figure 5: Radio frequency modem-RS485/ASIMET module at bow mast ............................................12

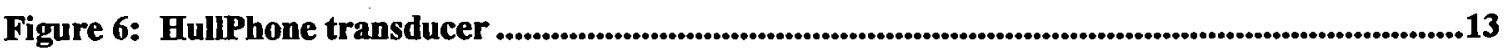

Figure 7: HullPhone on RV Oceanus frame at waterline............................................................................15

Figure 8: HullPhone RV Oceanus overhead frame (bridge ceiling) ......................................................16

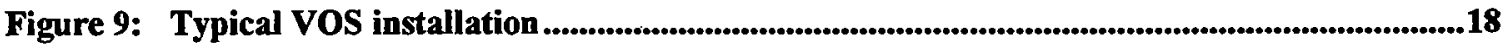

Figure 10: RV Oceanus-Acoustic and radio frequency test paths .......................................................19 


\section{Introduction}

In recent years increasing use has been made of Voluntary Observing Ships (VOS) to gather underway oceanographic and meteorological data. The XBT and meteorological measurement programs of D. Roemmich [Scripps Institution of Oceanography (SIO) VOS Group], R. Molinari [Atlantic Oceanographic Meteorological Laboratories (AOML) VOS Group], and towed measurements by T. Rossby [University of Rhode Island (URI) VOS Group] on the VOS Oleander operating between New York and Bermuda are recent examples. A major element of a shipboard installation of such instrumentation is the wiring that links sensors to data loggers and satellite transmitters. The wiring and the way in which the wires penetrate bulkheads must conform to US Coast Guard standards and are, therefore, expensive and difficult to install. Figure 1 shows a typical VOS container ship, the California Star. This report is on the feasibility of flexible, wireless means of signal transmission on ships.

\section{Background}

\section{A. The need for wireless data transmission}

Wireless data transmission is especially critical in the case of sea-surface temperature measurements made on the inside of the ship near the waterline. Figure 2 shows a sea-surface temperature VOS Improved METeorology (IMET) module installed in the California Star at the waterline. This hull-mounted measurement has been proven to be of much higher quality than those made at the seawater engine cooling intake; however, getting the data from sealed compartments that are low in the ship where the sensor is mounted is a special problem. Other applications include transmission of data from automated XBT launchers located on the aft deck to the science area, and transmission of data from a cluster of meteorological instruments located at the bow of the ship to the bridge for interface to Service Argos or Inmarsat satellite links. This type of bow installation could be battery powered and self-recording (almost a buoy configuration) that would be, because no cables are needed, ideal for VOS use. Figure 3 shows the bow mast on the Oceamus. Container ships, as an example of VOS, often do not have the convenient, protected cable runs common to research ships.

These problems are aggravated by the way in which present VOS operate. Many are fast container ships, whose operators seek minimal time in port. Thus, the port time during which equipment may be installed is brief, perhaps four hours. Installation of cables, if it needed to be done, would stretch out over many port calls. Drilling and installation of certified bulkhead fittings are required. The shifting around of hard-wired sensors to locations with less flow distortion, radio frequency interference, or stack gas contamination is a non-trivial task. In addition to short port stops, the ships' operators presently sell and replace ships on a given VOS route regularly, perhaps once a year. The SIO VOS Group had the experience of drilling through bulkheads over many port calls, installing the cable and then having the ship sold after the next cruise. Installation of a wireless system that 


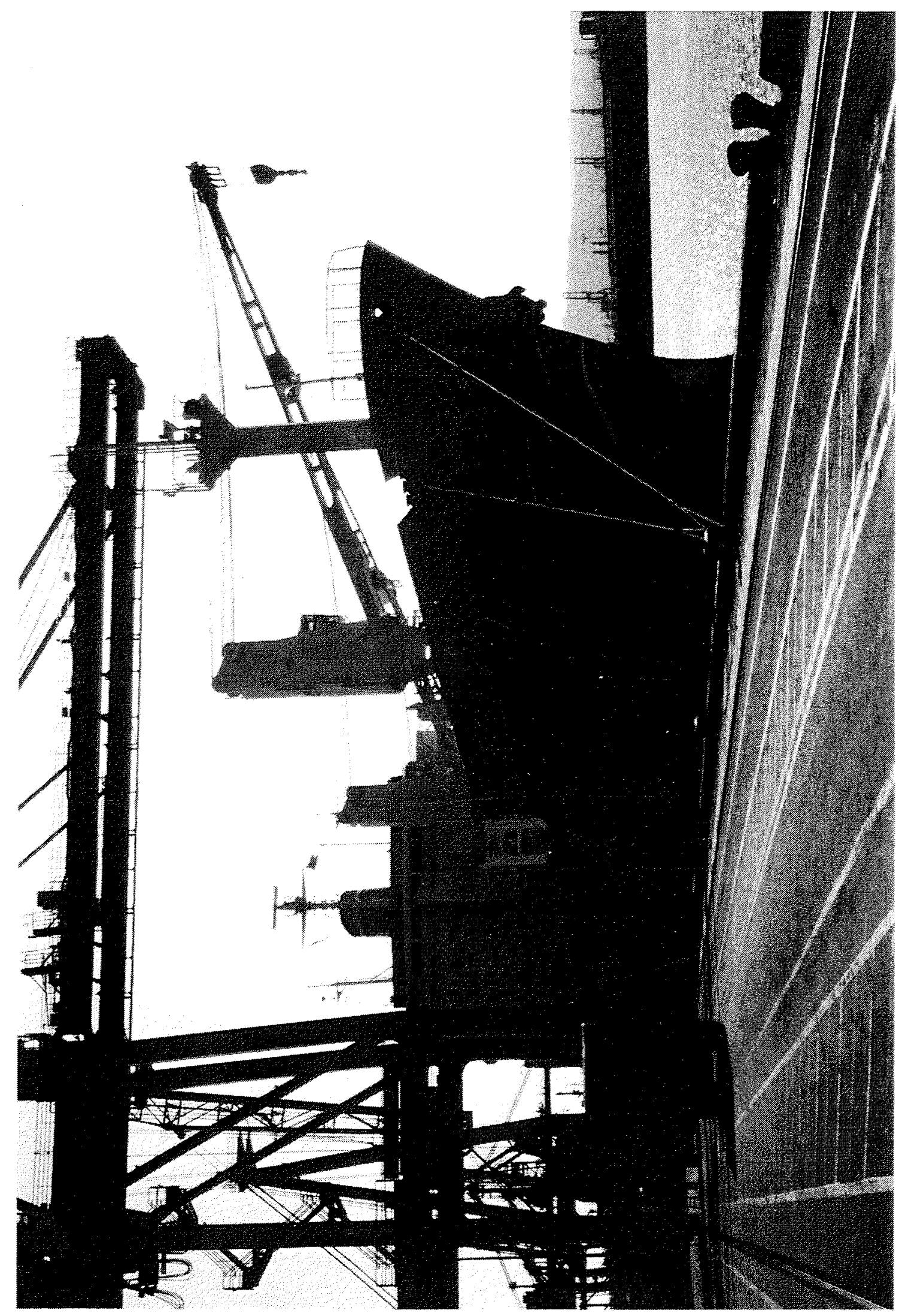

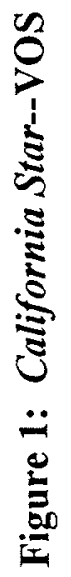




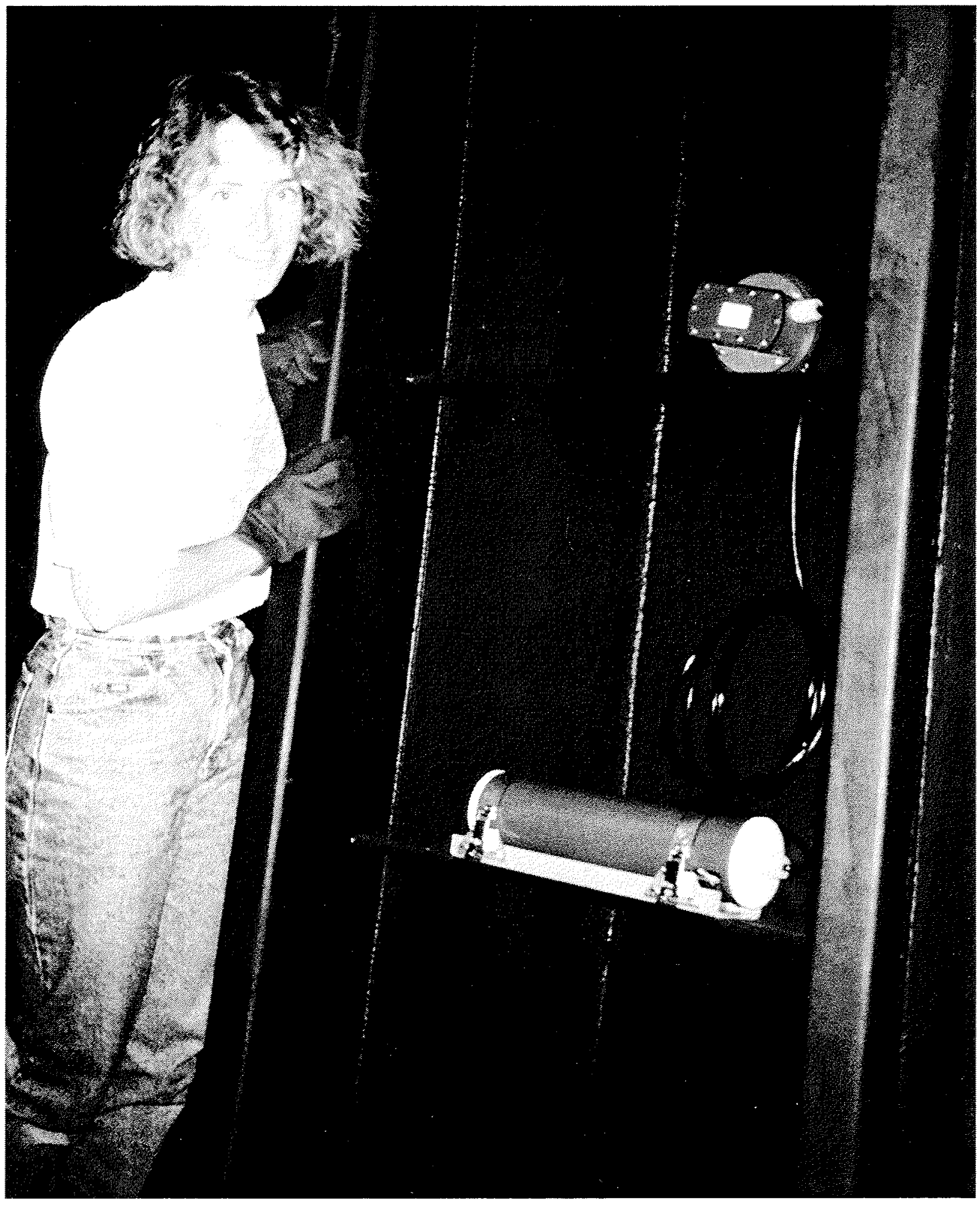

Figure 2: SST modules in hold of California Star 


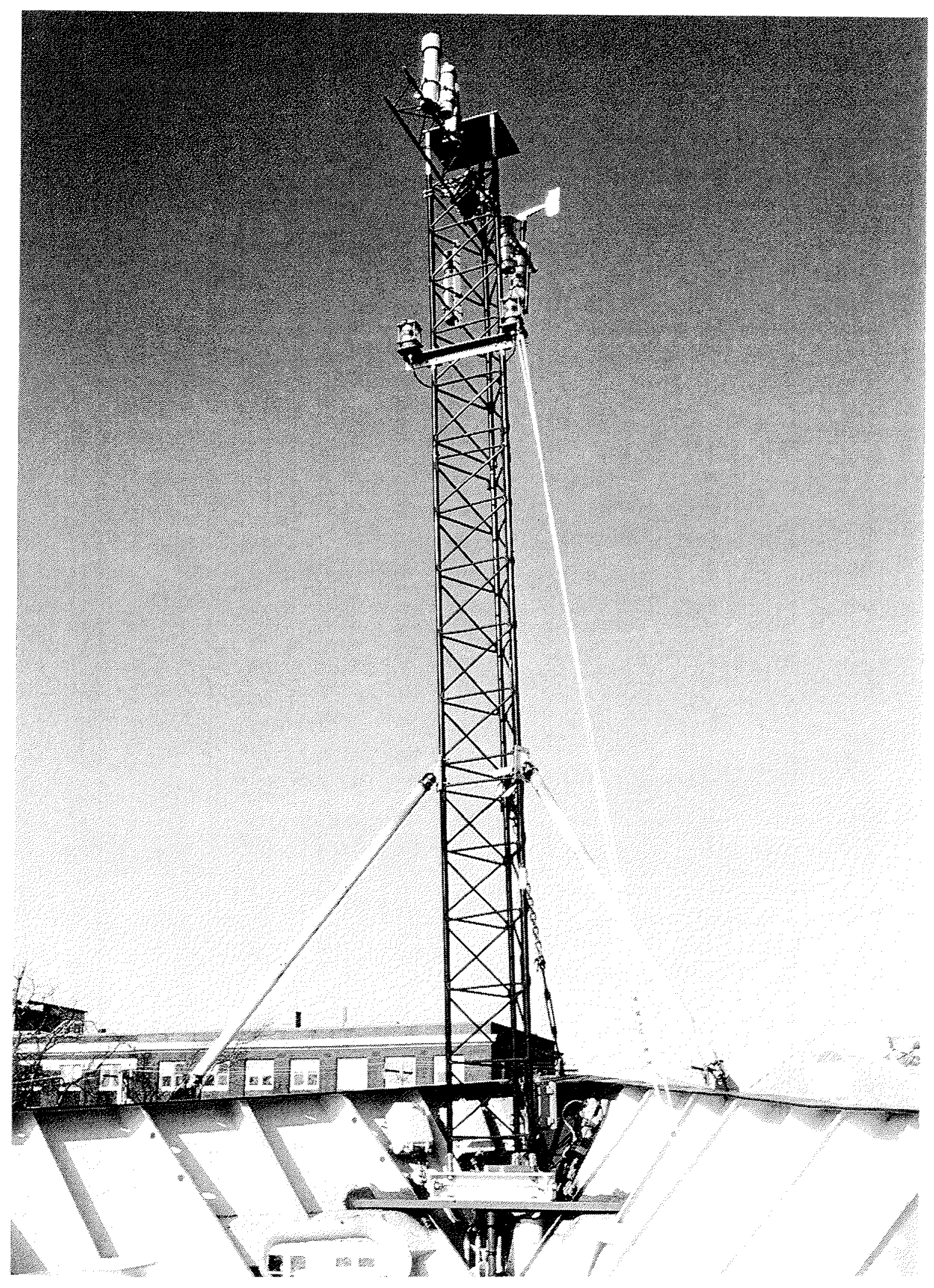

Figure 3: IMET on bow mast of RV Oceanus 
was battery operated could be done in one port call. While a hard-wired system would be difficult to shift to a new vessel, a wireless system could be moved easily. Furthermore, the logistical problems of trying to install equipment that cannot be hand carried on a ship include handling equipment availability, scheduling, and installation constraints based on jurisdiction and labor contracts. Real-time data, especially of sea-surface temperature (SST) and barometric pressure (BPR), are needed for initialization of numerical weather prediction models. In addition, ship operators want to see sensor data displayed (this facilitates establishing rapport with ships' owners and crew), and other users (satellite validation, etc.) need real-time transmission as well. Transmission also allows redundant data recording.

\section{B. State of the art of UOP-VOS}

The Upper Ocean Processes (UOP) Group at the Woods Hole Oceanographic Institution (WHOI) developed the original IMET modules under a grant from the National Science Foundation (NSF) for the World Ocean Circulation Experiment (WOCE) program (Hosom, et al., 1995). These modules have been used successfully on UniversityNational Oceanographic Laboratory System (UNOLS) ships and WHOI UOP buoys. These modules have been upgraded for lower power consumption for use on buoys and have provided excellent results on the Arabian Sea and Global Ocean Ecosystem Dynamics (GLOBEC) experiments. Recently, the IMET technology has evolved in new modules designed for use on VOS ships. These new VOS-IMET are self-powered (very low power), self-recording, stand-alone units that also are able to communicate on the IMET Addressable-Digital-Data Bus (ADDB). These units are being tested on VOS in cooperation with the SIO-VOS Group. The BPR unit and hull-mounted SST unit have been tested on the VOS California Star. The BPR and SST units plus the relative humidity/air temperature unit (HRH) and the wind speed/direction unit (WND) are being tested on the VOS Brisbane Star starting in the summer of 1997. A precipitation unit, short-wave radiation unit and long-wave radiation unit will be added to the test in 1998 and 1999 to complete the standard flux sensor suite. All of these units typically operate on eight alkaline D-cell batteries for six months and record up to 4 megabytes of data on a PCMCIA flash card. These stand-alone units provide one-minute samples in a data set processed after the cruise is finished, and the units are returned to the laboratory.

\section{Approaches}

These low-power VOS-IMET units are ideally suited for use in a wireless network. They do, however, need to transmit their data to a central logger/controller for transmission via satellite. There were three approaches tested in this program: (A) a radio-modem, (B) an acoustic modem, and (C) a power line signal injection system (similar to home control units). The results of the testing will be described in the following paragraphs. 


\section{A. Radio frequency modems}

There are a large number of commercially available "wireless data links" that operate at 900 and 450 megahert $z$ in a spread spectrum mode. These can be used as line-ofsight transmitters and as repeaters to get data from one point to another. These would be applicable between the bow and wheelhouse of a ship. An excellent reference is the article, "Spread spectrum challenges FM in wireless telemetry systems" (Schreier, 1996), that describes the various units and provides sources. A listing of companies is provided in Appendix 1. Units from two manufacturers were purchased. The first units were from Comrad Corp.(CRC) (specs in Appendix 2) that worked only on RS232 and were for inside use only. They worked well, were low cost (about $\$ 250$ ea.), and could provide a good link. They required high power (about $0.5 \mathrm{amps}$ at $12 \mathrm{vdc}$ ) and did not have a stand-by option. The second units were from Wireless Scientific Corp. (WSC) (specs in Appendix 2) that also worked well either on RS232 or RS485. They were more expensive (about $\$ 1,500$ for the all-weather unit and $\$ 1,250$ for the inside unit), and did have a "sleep" mode that conserved power. Power during operate mode was about the same as the CRC unit (about 0.5 amps at $12 \mathrm{vdc}$ ).

Both types of units tested on the WHOI ship RV Oceamus worked well in a line-of-sight mode but did not work through the ship superstructure. The WSC units used a RS232 unit on the bridge of the ship and an all-weather RS485 unit with the VOS-MMET module. Figure 4 shows the RS232 transmitter on the bridge and Figure 5 shows the RS485 transmitter with a VOS-IMET module at the base of the mast on Oceanus. This was quite convenient since the VOS-IMET units normally communicate via RS485. Other testing of the WSC units included communications from a shore building to an off-shore buoy. While the units were within line of sight, buoy motion in high winds did cause marginal transmission. The use of yagi antennas significantly improves communications and would be recommended for use on a ship. The low power "sleep" mode is critical for use in the buoy application or in a stand-alone bow mast meteorological application.

\section{B. Acoustic modem}

The second approach proposed was an acoustic modem. Other programs at WHOI in the area of acoustic data transmission through the water are well developed. Since the ship's hull is a good acoustic path, it was proposed to investigate this option. A reviewer of the proposal noted that SeaBeam, Inc. (SBI) had a development project underway similar to this. Contact with SBI confirmed this and a contract using the SBI prototype equipment with engineering support was written to do this testing. SBI is developing a device called a "HullPhone" for use in ships that have been damaged and do not have normal communications. The HullPhone has transducers that clamp to ships' frames (the clamp is custom designed for maximum acoustic coupling and is shown in Figure 6) and uses a $36 \mathrm{kHz}$ carrier, modulated with frequencies that range from $500 \mathrm{~Hz}$ to $3500 \mathrm{~Hz}$ (voice band). This is ideal for a frequency shift key (fsk) commercial modem that operates at 300 baud. The unit requires about 0.25 watts of power on standby and 10 watts of power on transmit. Testing on Oceanus determined that there was an excellent 


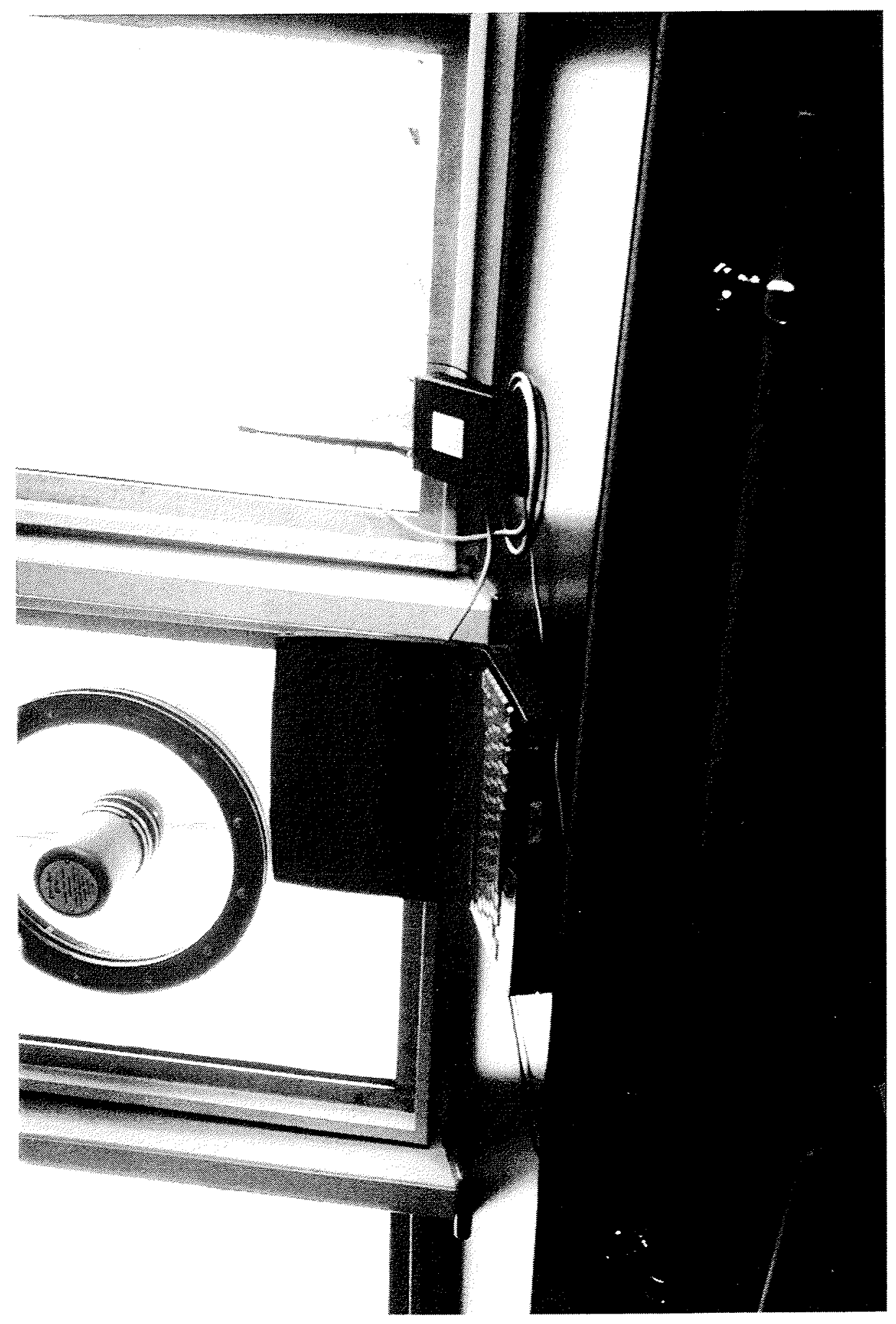

Figure 4: Radio frequency modem--Bridge RS232 unit 


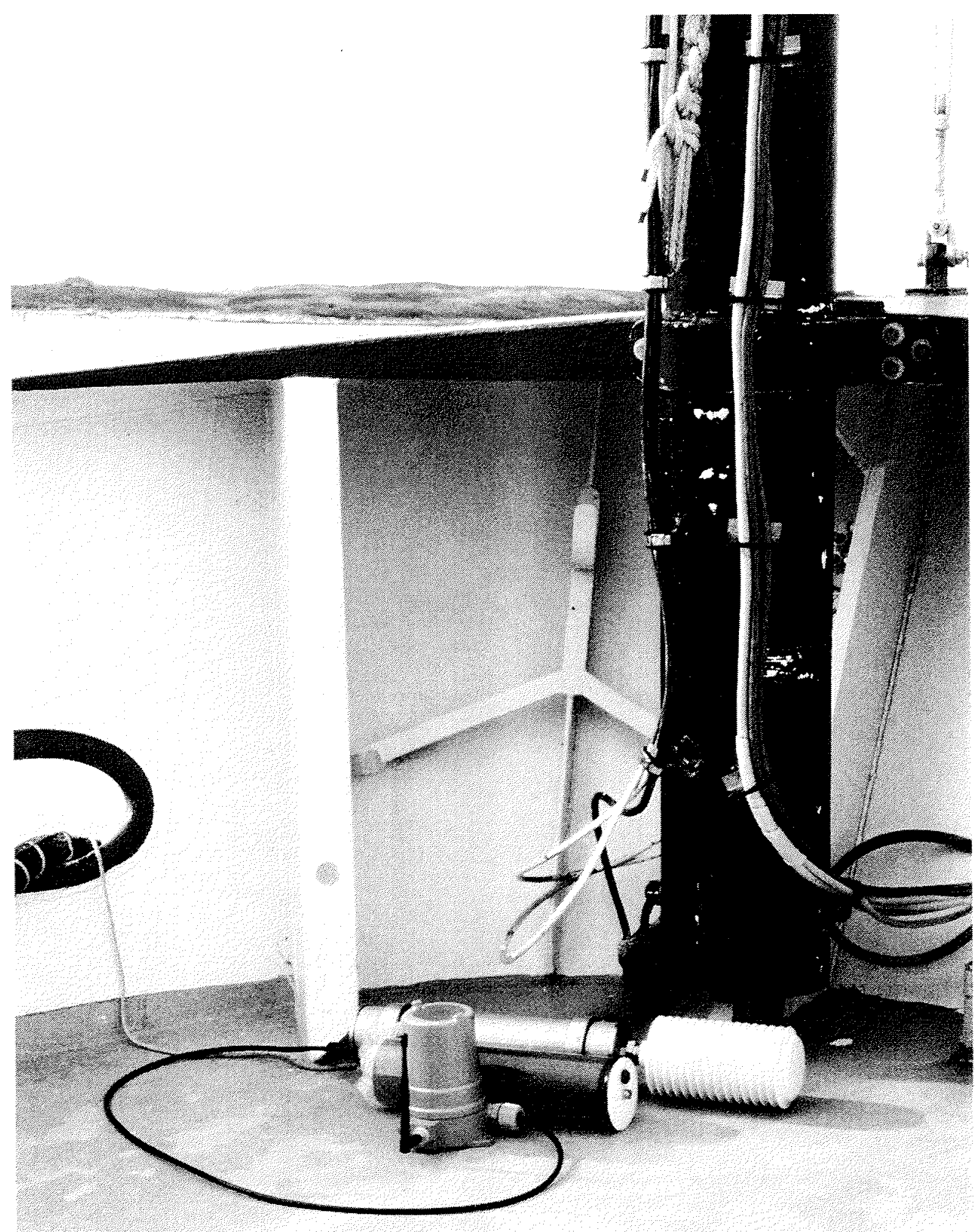

Figure 5: Radio frequency modem--RS485/ASIMET module at bow mast 


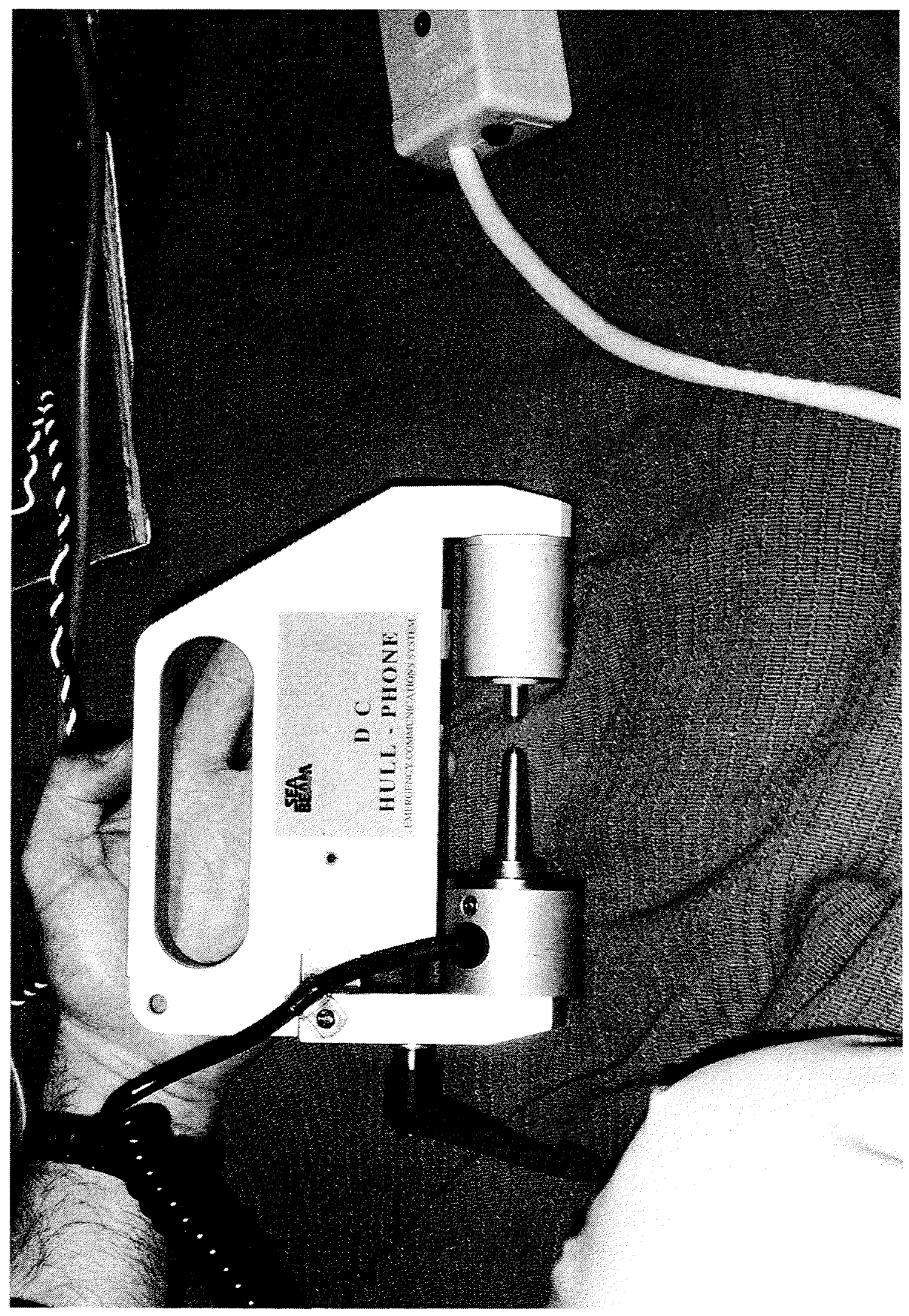

Figure 6: HullPhone transducer 
acoustic path (probably through the ship's hull instead of the frame). This path went from near the waterline to the top of the bridge roof. Figure 7 shows the HullPhone transducer installed on the frame at the waterline in Oceamus. Figure 8 shows the HullPhone installed in the ceiling of the bridge of Oceanus. The Oceanus has a steel hull and an aluminum superstructure. The acoustic path was excellent even through the steel/aluminum anticorrosion barrier. The acoustic path was both vertical and along-ship suggesting that this device would be able to provide a data path over much of the ship. The $36 \mathrm{kHz}$ carrier frequency is above the ship equipment and underway noise frequencies. The transmit source level had to be lowered significantly to have the receive signal in a linear range. In this mode, the receive signal had almost a $23 \mathrm{db}$ signal-to-noise ratio. .

The feasibility testing showed the acoustic modem to be a highly viable device for wireless shipboard data transmission. It is based on a proprietary program at SeaBeam, Inc. (SBI). SBI is pursuing further development of this device but it is expected that some custom design work will be required to produce a commercial device to meet the needs of a ship system. Funding for a development program will be required to meet specifications for a useful system. The success of this depends on the quantity of units needed.

\section{Power line coupling}

The third approach tested was power line coupling units $(\mathrm{X}-10)$ and telephone/power line units. The telephone units would seem to offer a good path but communication with the manufacturer determined that it could not be used. When a remote phone is picked up, no other phone can communicate.

The X-10 technology is used in houses to control lights and appliances from custom controllers or computer interface units. (See detail in Appencix 3). The computer interface units are capable of very slow data communications from one computer to another by using the X-10 command code structure. The X-10 system works on $60 \mathrm{~Hz}, 120 \mathrm{vac}$ power systems by placing a 1 millisecond modulated burst of $120 \mathrm{kHz}$ on the ac line. The burst is sent three times for each bit, once at each ac zero-crossing (based on a 3-phase system) since that gives the best signal-to-noise ratio for data transmission. In addition, each bit is sent both true and complemented, and each code sequence is sent twice. A single normal command takes eleven cycles of the ac line to finish. All legal commands must first start with the header (1110), followed by 4 bits of "house" code, concluded with 5 bits of "unit function" code. Two computer serial port interface boards and associated power line interface modules were purchased. The systems were set up for test on the bench. When it did not work, the manufacturer was called. It was noted that if there were any fluorescent lights on the line the X-10 system would require a special filter since electronic ballasts generate $120 \mathrm{kHz}$. Setting up the system on an isolated power strip resulted in good operation. However, this limitation means that the $\mathrm{X}-10$ system is not recommended for use on ships. 


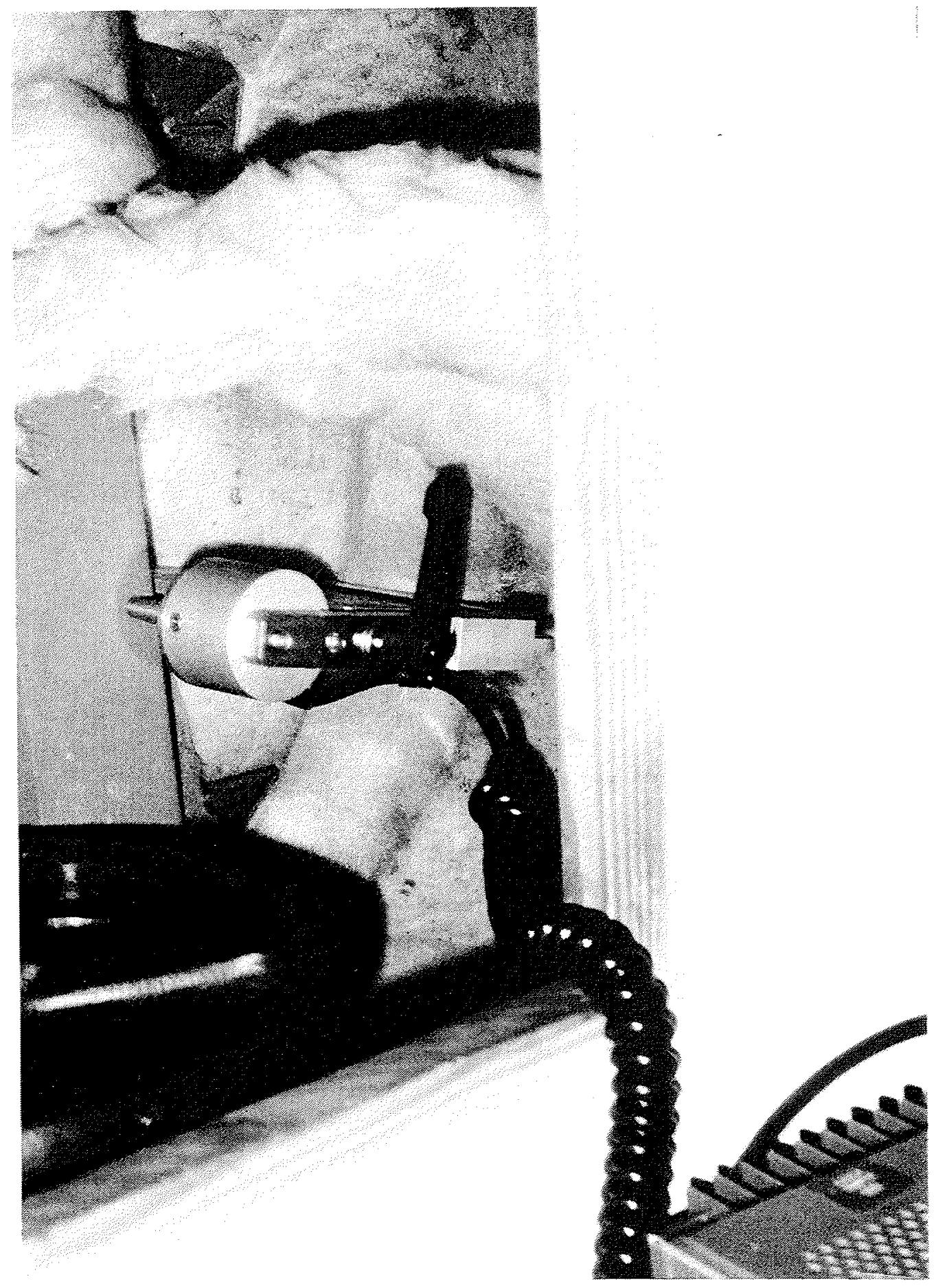

Figure 7: HullPhone on RV Oceanus frame at waterline 


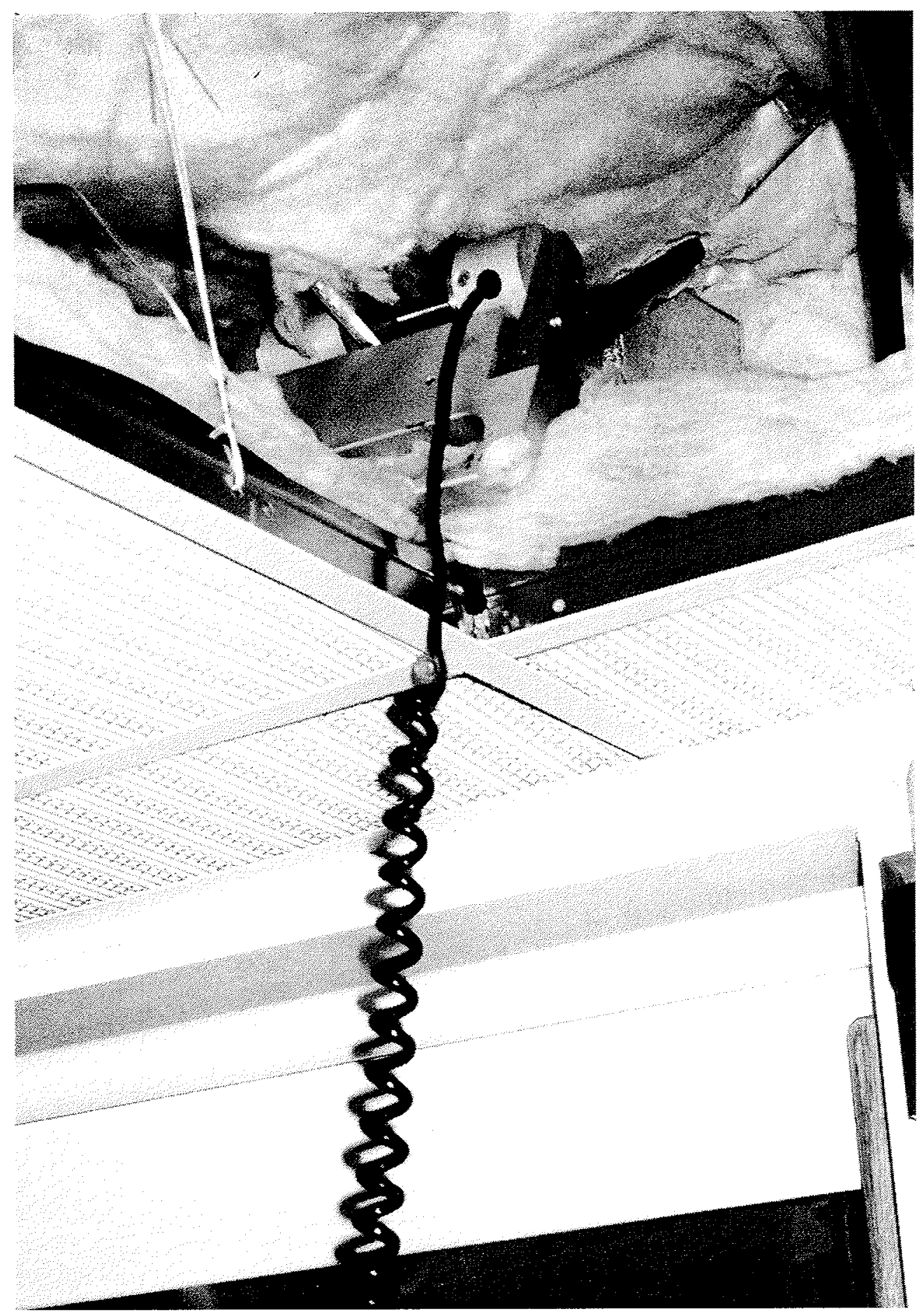

Figure 8: HullPhone RV Oceanus overhead frame (bridge ceiling) 


\section{Proposed future VOS installation}

- After investigating the feasibility of the various approaches to wireless data transmission on ships, it would be instructive to describe a "proposed future" VOS installation using the appropriate wireless data approaches. A block diagram of this proposed system is shown in Figure 9. The main bow mast meteorological installation would consist of an integrated suite of sensors with digital front-end interfaces and a battery powered data logger/controller. This system would also be suitable for use on a coastal buoy. Connected to the main bow mast meteorological system would be a separate battery powered RS485 radio frequency modem to provide communications to the ship's bridge and to an acoustic modem that links the SST module. The SST module would be a stand-alone module that is located inside the ship's hull at (or very near) the waterline. This is the recommended location based on the UK Met Office evaluation. (Kent et al., 1991). The battery-powered acoustic modem would provide communications between the SST and the main logger on a once-per-hour basis. The computer used to control the Inmarsat satellite communications would interrogate the main data logger on the bow mast on a once-per-hour basis via a radio frequency. modem. This would automatically send a high quality meteorological data record via satellite to the land-based meteorological network. This system is feasible using currently available components on research ships. An integrated system using only the minimum number of components that was designed for volume manufacture would lower the cost and permit high quality meteorological data to be obtained from a large number of VOS on a real-time basis.

\section{Summary}

In summary, each of the methods evaluated were feasible for ship wireless data transmission (with the exception of the telephone devices) with some limitations. The most serious problem at the start of the project was getting SST data from the ship waterline to the deck, and that is now shown to be feasible using the acoustic modem. The acoustic modem itself requires further development to be commercially available for use in recommended systems. The many radio frequency modems available commercially offer convenient choices for data transmission above deck where there is a line-of-sight from transmitter to receiver. These are listed in Appendix 1. The power line devices do not provide convenient devices that can be recommended at this time. Every ship will require some different approaches; the recommendations made in section 4 will probably be the most economical and productive.

Figure 10 shows the cross-section of the R/V Oceamus with the transmission paths for both the acoustic modem and the radio frequency modem. 


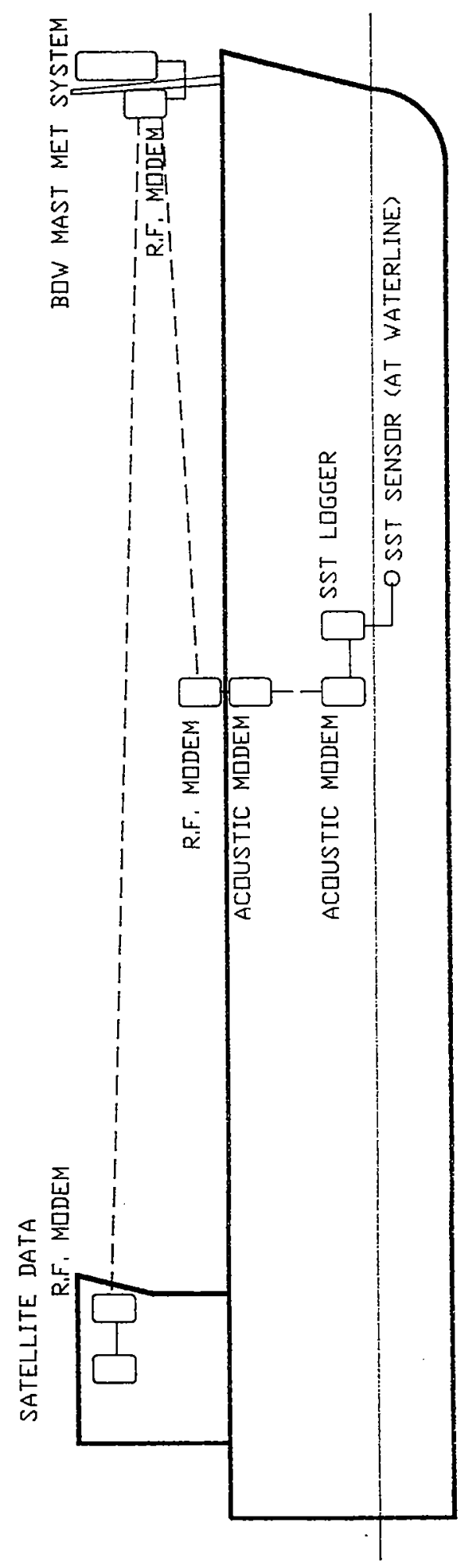

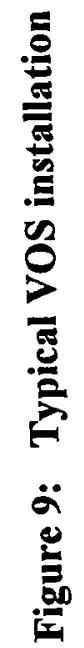




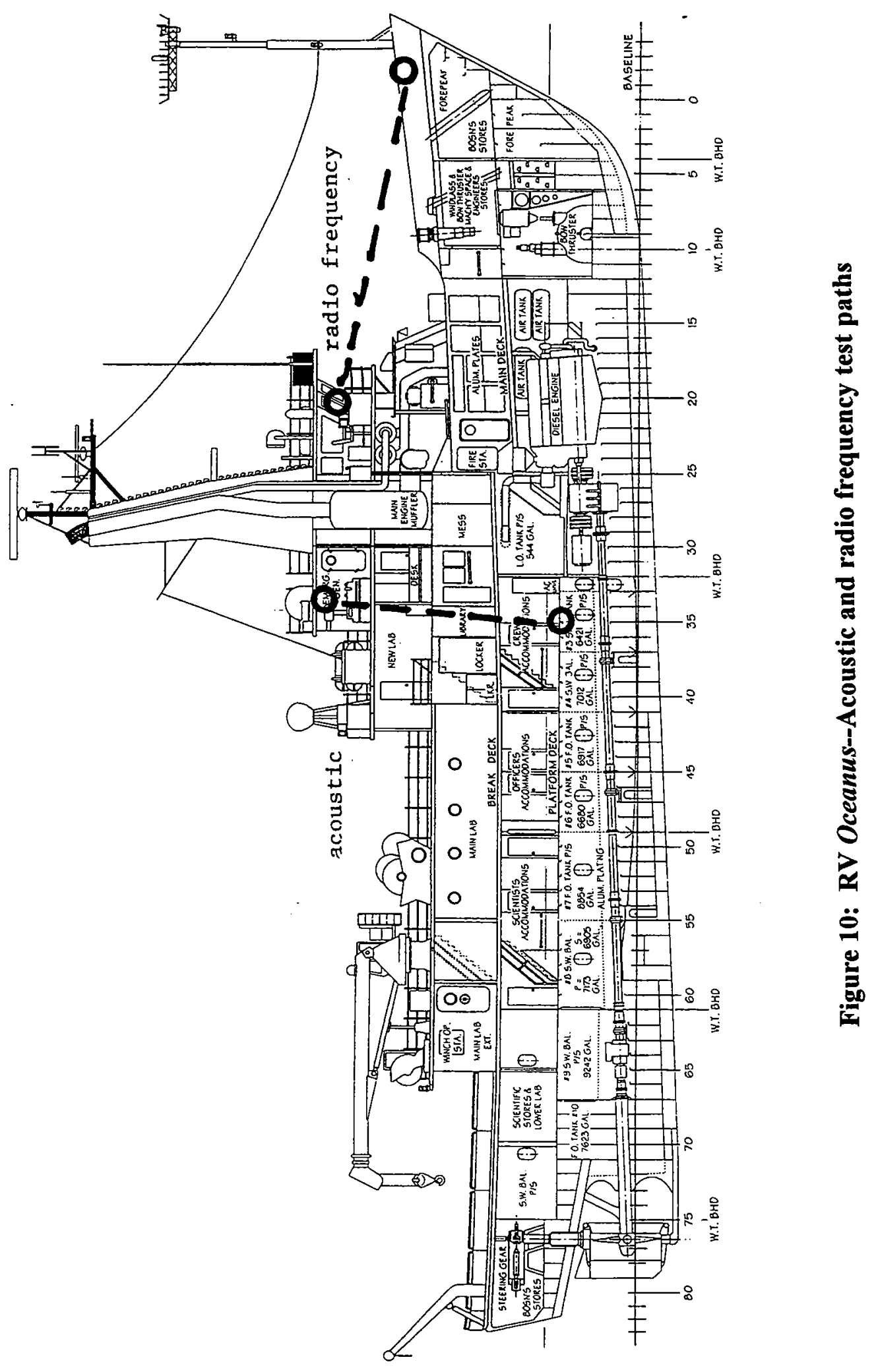




\section{Acknowledgments}

This project, "Feasibility of Wireless Data Transmission on Ships", was supported by NSF Award Number OCE96-32461 from the National Science Foundation, Ocean Science Division.

\section{References}

Hosom, David S., Robert A. Weller, Richard E. Payne, and Kenneth E. Prada, 1995. “The IMET (Improved Meteorology) Ship and Buoy Systems."- Journal of Atmospheric and Oceanic Technology, 12(3), 527-540.

Kent, E. C., B. S. Turscott, P. K. Taylor, and J. S. Hopkins, 1991. The accuracy of ship's meteorological observations: Results of the VSOP-NA. Marine Meteorology and Relatead Activities Report No. 26, World Meteorological Organization, Geneva, $86 \mathrm{pp}$.

Schreier, Paul G., Editor, 1996. "Spread spectrum challenges FM in wireless telemetry systems." Personal Engineering \& Instrumentation News, 3(2), 29-38. 
Appendix 1: List of radio frequency modem companies

October 16, 1996

Company:

Address:

Model No:

Frequency:

Power:

Contact/Phone:

Company:

Address:

Model No:

Frequency:

Power:

Contact/Phone:
Aerotron-Repco Systems Inc

2400 Sand Lake Road, Orlando, FL 32809-7680

SLR 96, Econolink

$900 \mathrm{Mhz}$ spread sprectrum, radio modem

10.5 to $13.8 \mathrm{vdc}$, xmit $750 \mathrm{ma}$, rec $450 \mathrm{ma}$

(407) 856-1953, (800) 950-5633

Aironet Wireless Communications, Inc.

PO Box 5292, Fairlawn, OH 44334-0292

Arlann 630, 631, 632, 640, 655, 670, 690

$900 \mathrm{Mhz}$, Direct Sequence Spread Spectrum Radio, LAN

1 watt EIRP, 18 vdc @ 1 amp, 300 milli watts

1-800-3-WIRELESS, 818-361-4918, http://www.aironet.com

Company (purchased) Communications Research and Development Corp.

Address:

Model No:

Frequency:

Power:

Contact/Phone:

Price:

Company:

Address:

Model No:

Frequency:

Power:

Contact/Phone:

Company:

Address:

Model No:

Frequency:

Power:

Contact/Phone:

Price:
7210 Georgetown Rd. \#300-400, Indianapolis, IN 46268

CCL901-DP

$900 \mathrm{Mhz}$

7 to $16 \mathrm{vdc}$, xmit $190 \mathrm{ma}$, rec $135 \mathrm{ma}$, pwr up 120 millisec

(317) 290-9107

$\$ 450 /$ pair

Curry Controls Co.

PO Drawer 5408, Lakeland, FL 33807

Modpac Plus

400-500 Mhz, Synthesized UHF

$12.5 \mathrm{vdc}, 120 \mathrm{ma}$. 2 watt, $3-5$ watt.

(941) 646-5781, fax (941) 6463899

Digital Wireless Corp.

One Meca Way, Norcross, GA 30093

WIT915

900 Mhz, Recombinant Spread Spectrum, 21 channels

7 to $10 \mathrm{vdc}$, xmit 195 to $452 \mathrm{ma}$, rec $122 \mathrm{ma}$, sleep 750 ua

(770) 564-5540, fax 770-564-5541, mkting@digiwrls.com $\$ 850$ ea 


\begin{tabular}{|c|c|}
\hline Company: & Fluke Corporation \\
\hline Address: & PO Box 9090, Everett, WA 98206 \\
\hline Model No: & 2625A-WL \\
\hline Frequency: & $900 \mathrm{Mhz}$ spread spectrum \\
\hline Power: & 9 to $9.5 \mathrm{vdc}$ at $3 \mathrm{VA}$ \\
\hline Contact/Phone: & (800) $443-5853$ \\
\hline Price: & $\$ 3,995$ \\
\hline Company: & FreeWave Technologies, Inc \\
\hline Address: & 1880 South Flatiron Court, Boulder, CO 80301 \\
\hline Model No: & DGR-115 \\
\hline Frequency: & 902-928 Mhz, spread spectrum xcvr \\
\hline Power: & 10.5 to $18.0 \mathrm{vdc}$, xmit $180 \mathrm{ma}$, rec $100 \mathrm{ma}$ \\
\hline Contact/Phone: & (303) 444-3862 \\
\hline Price: & $\$ 1,250 \mathrm{ea}$ \\
\hline Company: & GRE America Inc. \\
\hline Address: & 425 Harbor Blvd., Belmont, CA 94002 \\
\hline Model No: & Gina $6000 \mathrm{NVK}$ \\
\hline Frequency: & $900 \mathrm{Mhz}$, spread spectrum, packetized /error det \\
\hline Power: & $12 \mathrm{vdc}$, xmit $750 \mathrm{ma}$, rec $450 \mathrm{ma}$ \\
\hline Contact/Phone: & (415) $591-1400,(800) 233-5973$ \\
\hline Company: & Instrumented Sensor Technology \\
\hline Address: & 4704 Moore St; Okemos, MI 48864 \\
\hline Model No: & Field Link \\
\hline Frequency: & $850 \mathrm{Mhz}$ Cellular \\
\hline Power: & $12 \mathrm{vdc}, 0.75 \mathrm{ams}$ (has 4 ah batteries $=3 \mathrm{hrs}$ on time) \\
\hline Contact/Phone: & (517) $349-8487$ \\
\hline Company: & Monicor Electronic Corp \\
\hline Address: & 2964 NW 60th Street, Ft. Lauderdale, FL 33309 \\
\hline Model No: & IC-100 \\
\hline Frequency: & 406-420 Mhz, 25 channels \\
\hline Power: & $7.5 \mathrm{vdc}$, xmit $180 \mathrm{ma}$, rec $40 \mathrm{ma}$ \\
\hline Contact/Phone: & (305) 979-1907 \\
\hline Company: & O’Neill Communications, Inc. \\
\hline Address: & 8601 Six Forks Rd., Raleigh, NC 27615 \\
\hline Model No: & LAWN II- 232, -DGT (485) \\
\hline Frequency: & $900 \mathrm{Mhz}$, FSK spread spectrum \\
\hline Power: & $12 \mathrm{vdc}, 250 \mathrm{ma}$ \\
\hline Contact/Phone: & (215) $830-1200$ \\
\hline Price: & $\$ 275$ each \\
\hline
\end{tabular}




\begin{tabular}{|c|c|}
\hline Company: & Pacific Crest Corp. \\
\hline Address: & 2285 Martin Ave, Suite A, Santa Clara, CA 95050 \\
\hline Model No: & RFM96 \\
\hline Frequency: & 150 to $512 \mathrm{Mhz}$ \\
\hline Power: & 10 to $15 \mathrm{vdc}$, xmit $1 \mathrm{a}$, rec $100 \mathrm{ma}$ ( $2 \mathrm{w}$ unit) $15 \& 35 \mathrm{w}$ avail \\
\hline Contact/Phone: & (800) 795-1001, (408) 653-2070 paccrst@ix.netcom.com \\
\hline Price: & $\$ 1,098$ std, $\$ 1,235$ rugged \\
\hline Company: & RF Neulink (RF Industries) \\
\hline Address: & 7610 Miramar Road, San Diego, CA 92126-4202 \\
\hline Model No: & Neulink 9600 \\
\hline Frequency: & 403 to $512 \mathrm{Mhz}$ ( 6 channels) \\
\hline Power: & $10-15 \mathrm{vdc}$, xmit $900 \mathrm{ma}$, rec $100 \mathrm{ma}$ \\
\hline Contact/Phone: & (800) $233-1728,(619) 549-6340$ \\
\hline Company: & Wireless Scientific Inc. \\
\hline Address: & 1890 South 14th St, Amelia Island, FL 32034 \\
\hline Model No: & CK-232 M \\
\hline Frequency: & $900 \mathrm{Mhz}$, spread spectrum \\
\hline Power: & $12-24 \mathrm{vdc}, 500 \mathrm{ma}$ \\
\hline Contact/Phone: & (904) 261-6977 Attn Rick Schweitzer \\
\hline Price: & $\begin{array}{l}\$ 1,298 \text { std, } \$ 1,598 \text { all weather, } \$ 1,948 \text { hazardous area } \\
\text { (loan available) }\end{array}$ \\
\hline
\end{tabular}




\section{Appendix 2: Data sheets}

\section{A. Comrad modem}

\section{How to Get from Point A to Point B with no Strings Attached.}

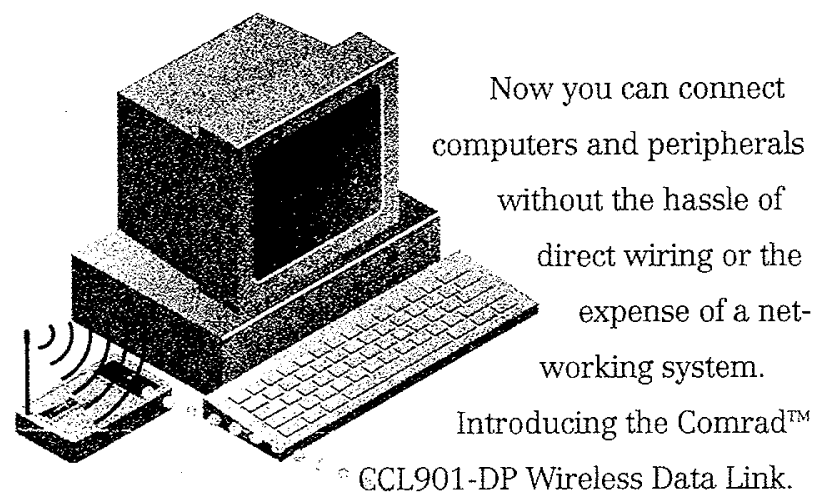

Comrad is the most convenient and affordable solution for data-sharing and file-transfer between computers. Down load your notebook to your desktop or connect one or more computers to a laser printer, scanner, other peripheral, or existing network system.

Using a 900 Mhz radio frequency, Comrad provides a wireless point-to-point link transfer-even if separated ings - with a speed of up to

Comrad features a range the office or home and in the distance can extend to additional Comrad units as ther extend the operating

No FCC license is required. Operates at $900 \mathrm{Mhz}$.
Comrad assures compatibility between hardware and software by featuring both full duplex and half duplex. It's easily installed and connects to any device with a standard RS232 serial port. No technical training is required.

Portability is possible with Comrad's rechargeable compact battery pack. This user-installed option combines mobile flexibility with instant access to another computer or peripheral.

Ready to work virtually right out of the box, Comrad includes powerful computer linkage software, bundled at no extra charge.

The Comrad CCL901-DP package comes complete with two Comrad CCL901 transceiver units, compatible software, two power adapters, two serial cables and user manuals-all for only $\$ 449.95$

(Suggested retail).

For more information about Comrad, call

317-290-9107, ask for Jenny.

$1 / 3$ mile. The use of transponders can furrange.

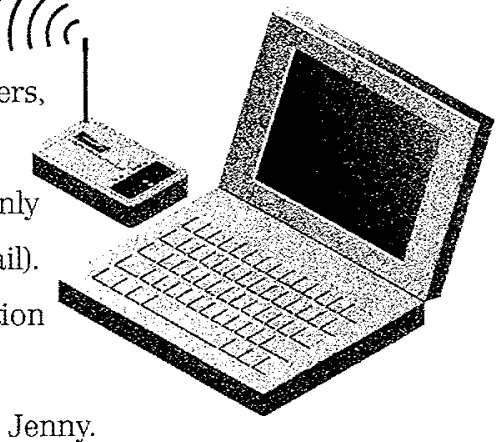

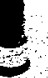

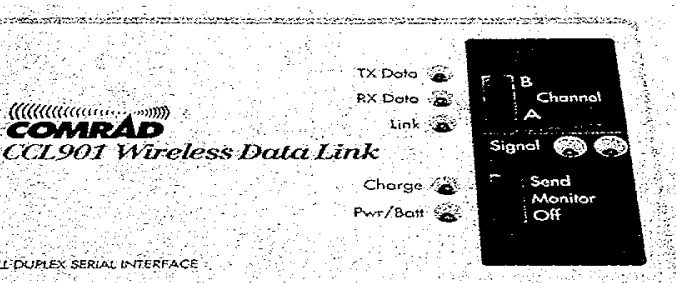

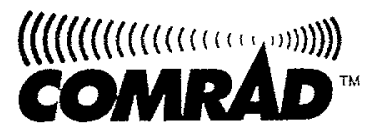

Made in USA

Corrad is a tracernak of Devetoment Conpration. 


\section{APPLICATIONS}

Where there are computers or peripherals that need to be linked and direct wiring is inconvenient or too expensive, The Comrad CCL901-DP is the most convenient and affordable solution to get from Point A to Point B.

For the home or office, Comrad provides a wireless link to share data and programs between computers, including transfers from a notebook to a desktop. Comrad is also the wireless solution between a computer and a laser printer, scanner, plotter or other peripheral. Comrad also provides wireless access from a remote computer to a peripheral that is connected to another computer.

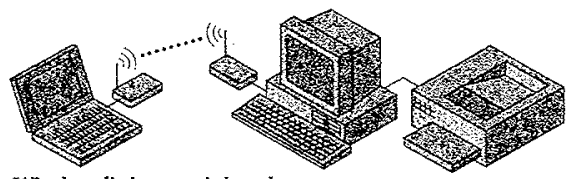

Wireless link to peripheral via another compuler.

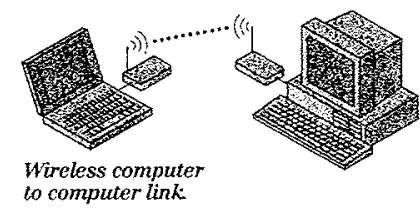

to computer link:

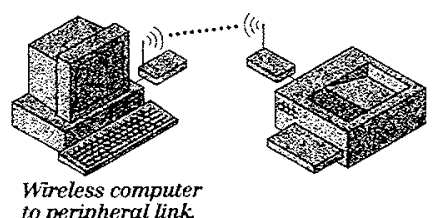

to peripheral link.
In an office situation where multiple computers need to be connected to one peripheral, additional Comrad units provide a convenient wireless solution. Multiple Comrad units can be used to develop a wireless system at a fraction of the cost of a conventional hard-wired LAN system. In addition, Comrad can serve as a wireless adjunct to an existing LAN system.
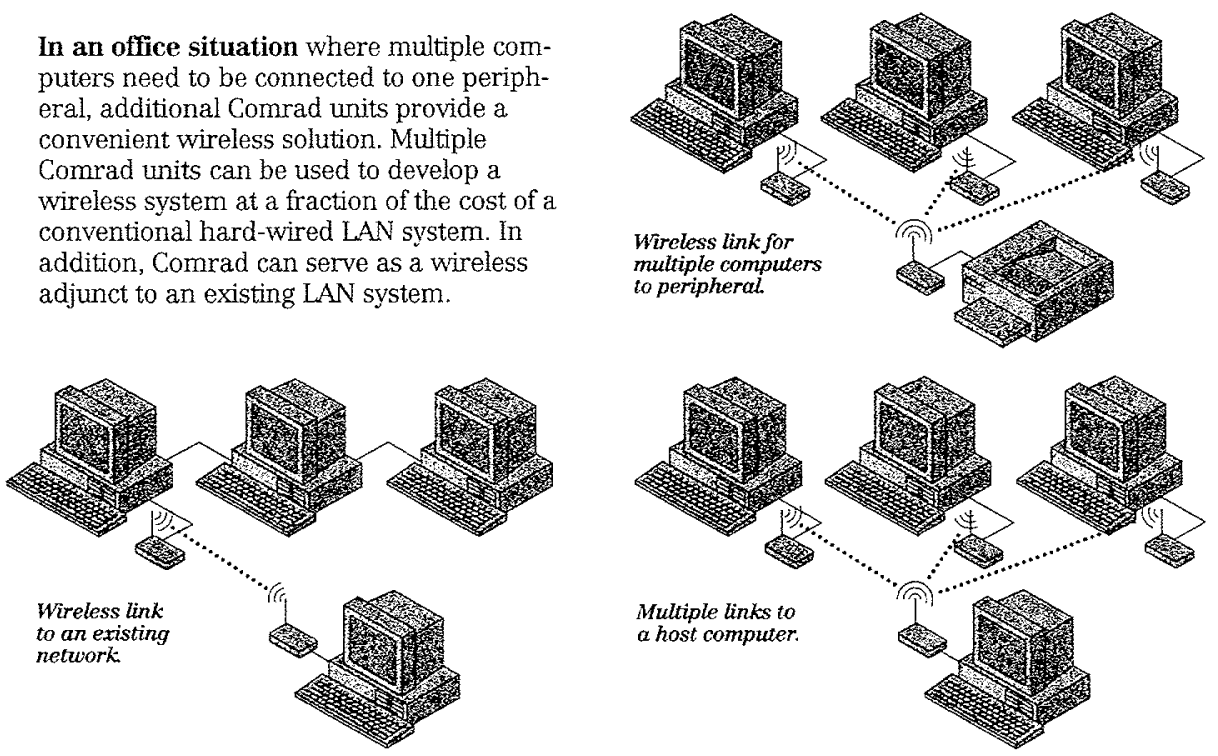

For remote programming or control of scientific, medical or industrial equipment, Comrad provides the low-cost solution with convenience-especially for linkage to a computer located within a unaccessible or hazardous area.

In either a warehouse or retail store, Comrad makes available a wireless link between a central computer and a transportable or can be used as a wireless remote link from a host computer to a bar code reader.
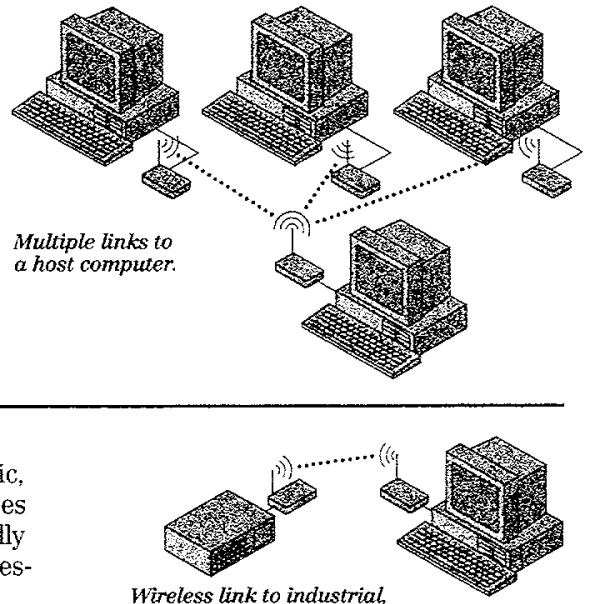

Wireless link to industrial scientific or medical equipment.

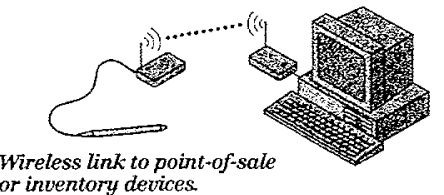

or inventory devices.

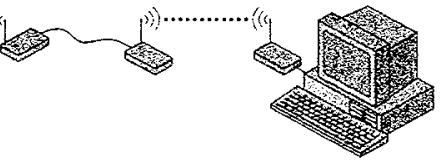

\section{FEATURES}

- Contrects to any dence with a starteardRS232 serfal port

- Allows thil anse of all of your oxisting software

- As transparent as a hard wired connection

- Trehides now erful camputer linkage sof ware at ho eharge

- Mourts on desk wall computer

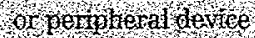

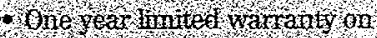
iods and a wor

Frequench fanges 002 to $928 \mathrm{MHz}$

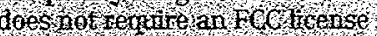

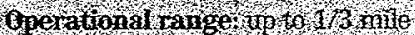

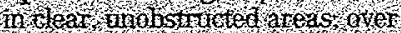

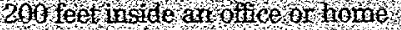

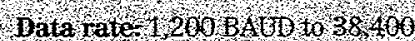

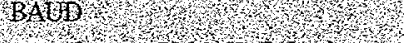

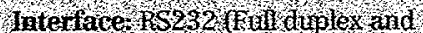

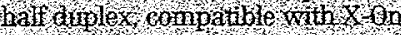

$x 00$

Multichannel oporation. operates

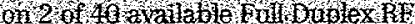
chanels

Antenna- user reglaceabole 4 /2 foedbie rublert yoe

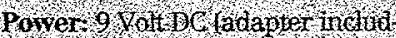
ed. UI 1 pproved.

Shpping weight $5 \mathrm{tb}$

Dinersions:

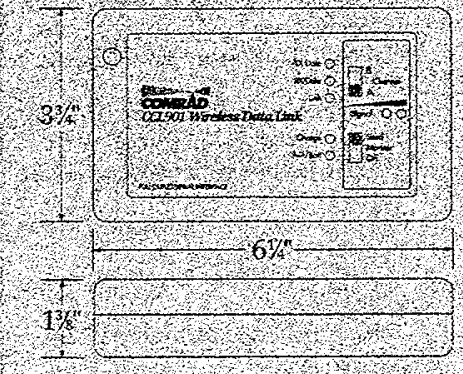

\section{Options:}

- 8 hour rechargeable $\mathrm{N}-\mathrm{Cad}$

Battery Pack $-\$ 99.95$

- Beltiolder $\$ 4995$

- Additionald J901 Transceviver \$21995 (Suggested Retail)

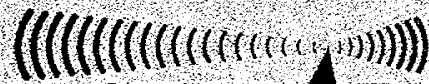 COMRAD}

7210 Georgetown Road sute $300 / 400$ Indianapolis, Indiana 46268

Phone, 317-290-9107

Fax:317-291-3093 


\section{Appendix 2, B: Wireless Scientific CK-232X}

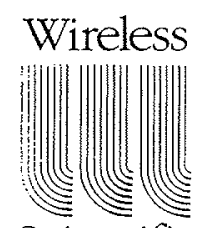

Scientific
CK-232X

Wireless Industrial Transceiver

Product Bulletin 9511-232X

The CK-232X Wireless Industrial Transceiver provides a "wireless communication bridge" between RS-232 industrial field devices. The CK-232X is designed for use in hazardous area locations classified as Class 1 , Division 1, Groups C, and D. Ratings include FM, CSA and NRTL (UL standard 508, 913, \& 1203).

The technology allows RS-232 field devices to communicate data wireless, via radio telemetry, thereby, eliminating all wiring, rigid conduit, installation labor expense, and the plant down-time typically associated with hard wiring a pair of RS-232 field devices. The product utilizes a sophisticated radio communication technique termed "spread spectrum". Operating at $900 \mathrm{MHz}$. a pair of transceivers may be radio linked, in order to communicate data up to a range of 15 miles, which far exceeds the maximum transmission distance, as specified for RS-232 wired systems. Spread spectrum telemetry requires no FCC license and no FCC site approval prior to use, as required by conventional radio communication techniques. The product may be used where new RS-232 field devices are being installed, or it may be used to replace aged wiring. as found with many pre-existing RS-232 field systems. The product may be paired with another CK-232X transceiver, or it may be paired with other Wireless Scientific telemetry products, such as a CK-232X paired with a CK-485X. Paired devices may be linked in a point-to-point, or point-to-multi-drop configuration.

Wireless Scientific products include: $\mathrm{CK}-232, \mathrm{CK}-485$, CK- $300 \mathrm{H}$ (Hart@ hardware interface), and CK-420 (4-20mA). Products are available for non-hazardous locations (safe areas), as well as, hazardous area locations.

\section{APPLICATIONS:}

- Remote Data Acquisition

- Process Monitoring and Control

- Safety Shutdown Control

- Industrial/Commercial Security

- EPA Regulatory Compliance

- Mobile Data 


\begin{tabular}{|c|c|}
\hline FEATURES: & ENEFITS: \\
\hline Cost effective & Less costly than most wired RS-232 communication installations \\
\hline Reliable & $\begin{array}{l}\text { Provides higher level of data integrity than many wired } \\
\text { communication systems }\end{array}$ \\
\hline Approved for Hazardous Locations & $\begin{array}{l}\text { May be used with new or existing field products located in } \\
\text { (Class } 1 \text {, Division } 1 \text {, Groups } C \text { and D) hazardous area locations }\end{array}$ \\
\hline Compact size & Enhances mounting to field products \\
\hline No conduit/cabling required & Reduces installation costs \\
\hline Easy installation & Minimizes time for equipment instailation and plant down-time \\
\hline Patented Spread Spectrum RF Technology & Provides superior noise and interference immunity \\
\hline Maximum RF Output Power & Enhances communication range between RS-232 devices \\
\hline Protocol transparent & Utilizes existing software applications \\
\hline Unlicensed Operation (FCC Part 15). & Requires no user fees or FCC site licensing \\
\hline Frequency Agile & $\begin{array}{l}\text { Provides clear channel communications even in congested RF } \\
\text { environments }\end{array}$ \\
\hline Low power consumption & Suitable for mobile and solar applications \\
\hline \multicolumn{2}{|l|}{ CK-232X SPECIFICATIONS: } \\
\hline Certification & $\begin{array}{l}\text { FM, CSA, and NRTL (UL standard 508, } 913 \& 1203 \text { ) for } \\
\text { Class 1, Division } 1 \text { Groups C, and D }\end{array}$ \\
\hline Enclosure & $\begin{array}{l}\text { All weather instrumentation enclosure, rated for Class } 1 \text {, } \\
\text { Division } 1 \text { Groups } C \text {, and D }\end{array}$ \\
\hline RF Frequency & $902-928 \mathrm{MHz}$ direct sequence spread spectrum \\
\hline FCC Certification & Certified under FCC Part 15 \\
\hline Power Output & $28.5 \mathrm{dBm}$, approximately $1 \mathrm{Watt}$ \\
\hline Antenna & $\begin{array}{l}\text { Standard antenna: External whip } \\
\text { Optional antenna: Mast mountable } 6 \mathrm{~dB} \text { Yagi for enhanced } \\
\text { range performance }\end{array}$ \\
\hline Operating Range & $\begin{array}{l}\text { Standard whip: } 1,000 \mathrm{ft} \text {. to } 2.5 \text { miles, line-of-sight (typical) } \\
\text { Optional Yagi: } 7.5 \text { miles half duplex, line-of-sight (typical) }\end{array}$ \\
\hline Asynchronous Data Rates & $\begin{array}{l}300,1200,2400,4800,9600,14.4 \mathrm{~K}, 19.2 \mathrm{~K} \text { bps full duplex } \\
300,1200,2400,4800,9600,14.4 \mathrm{~K}, 19.2 \mathrm{~K}, 38.4 \mathrm{~K} \text { bps half duplex }\end{array}$ \\
\hline Power Requirements & 120 VAC (std.) or $12-24$ VDC @ 600mA (optional) \\
\hline RS-232 & 9 position screw connection terminal strip \\
\hline Operating Temperature & $-40^{\circ} \mathrm{C}$ (with optional heater) to $+85^{\circ} \mathrm{C}$ \\
\hline Dimensions & 5.50"W X 7.75"D X 17.50"H (includes extended whip antenna) \\
\hline \multicolumn{2}{|c|}{ Specifications subject to change without prior notice. } \\
\hline $\begin{array}{l}\text { Wireless } \\
\text { Scientific } \\
\text { 1890 South 14th Street } \\
\text { Building 100. Suite 105 } \\
\text { Amelia Istand, FL 32034 } \\
904 \text { 261 6977 Fax 904 261 2129 }\end{array}$ & $\begin{array}{r}\text { Printed in U.S.A. } \\
\text { Copyright } 91995 \text { Wircless Scientific. Inc. } \\
\text { Product Bulletin } 9511-232 X\end{array}$ \\
\hline
\end{tabular}




\section{Appendix 2, C: Wireless Scientific CK-232}

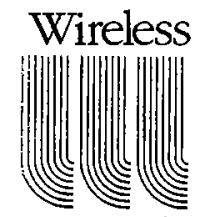

Scientific
CK-232

Wireless Industrial Transceiver

Product Bulletin 9511-232

The CK-232 Wiress Indusial Transcer provides a "wireles communication bridge" The CK-232 Wireless Industrial Transceiver provides a "wireless communication bridge" communicate data wireless, via radio telemetry, thereby, eliminating all wiring, rigid conduit, installation labor expense, and the plant down-time typically associated with hard wiring a pair of RS-232 field devices. The product utilizes a sophisticated radio communication technique termed "spread spectrum". Operating at $900 \mathrm{MHz}$, a pair of transceivers may be radio linked, in order to communicate data up to a range of 15 miles, which far exceeds the maximum transmission distance, as specified for RS-232 wired systems. Spread spectrum teiemetry requires no FCC license and no FCC site approval prior to use, as required by conventional radio communication techniques. The product may be used where new RS-232 field devices are being installed, or it may be used to replace aged wiring, as found with many pre-existing RS-232 field systems. The product may be paired with another CK-232 transceiver, or it may be paired with other Wireless Scientific telemetry products, such as a CK-232 paired with aCK-485. Paired devices may be linked in a point-to-point, or point-to-multi-drop configuration.

Wireless Scientific products include: $\mathrm{CK}-232, \mathrm{CK}-485, \mathrm{CK}-300 \mathrm{H}$ (Hartahardware interface), and CK-420 (4-20mA). Products are available for non-hazardous locations (safe areas), as well as, hazardous area locations classified as Class 1, Division 1, Groups C, and D. Ratings include FM, CSA and NRTL (UL standard 508, 913, \& 1203).

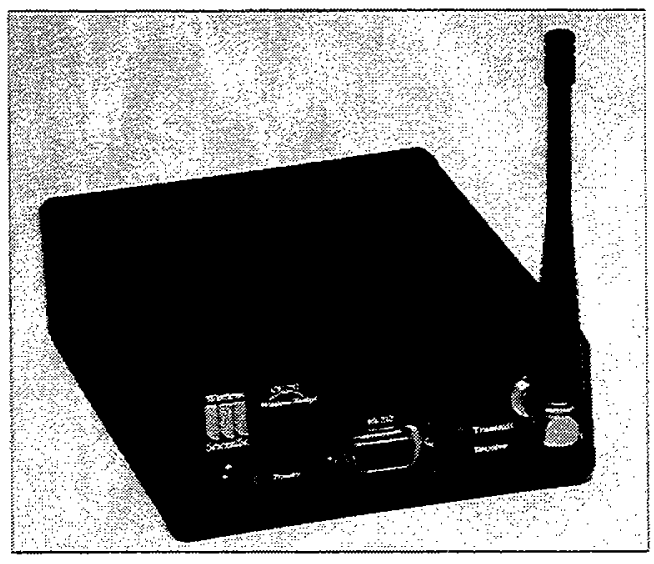

Spread Spectrom

"Wireless Bridge" for RS-232 devices

\section{APPLICATIONS:}

- Remote Data Acquisition

- Process Monitoring and Control

- Safety Shutdown Control

- Industrial/Commercial Security

- EPA Regulatory Compliance

- Mobile Data 


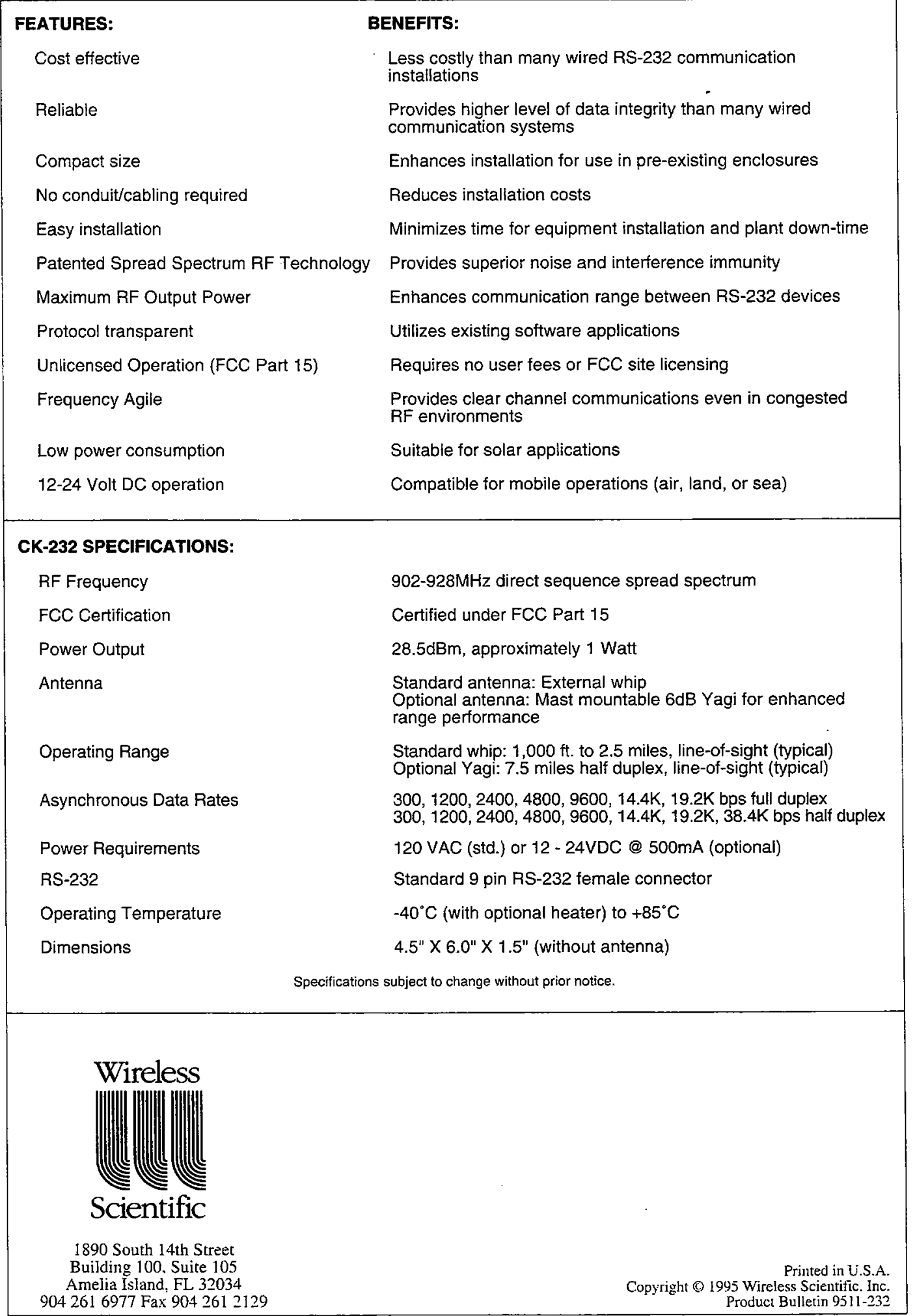




\title{
Appendix 3: Technical information
}

\author{
A. X-10 Modules protocol
}

\section{FAQ section 3 : Details on X10 Protocol}

Note: This section applies to $60 \mathrm{~Hz}$ North American wiring. Relevance of this to European wiring is not known.

Each ONE bit in a legitimate $\mathrm{X} 10$ transmission is a 1 millisecond (mS) pulse code modulated burst of $120 \mathrm{KHz}$ on the $\mathrm{AC}$ line, and each ZERO is the absence of that burst. The exact length of the burst may not be too critical in most applications. The burst is sent three times for each bit, once at each AC zero-crossing (accounting for zero-crossing in 3-phase). That means once each $2.778 \mathrm{mS}$. The next bit is sent on the following zero-crossing. This is done to get the quietest time on the AC line for the receiver, whatever phase of the AC it's on. The zero crossing gives the best signal-to-noise ratio for data transmission because everything should be shut down then (i.e. the voltage is low).

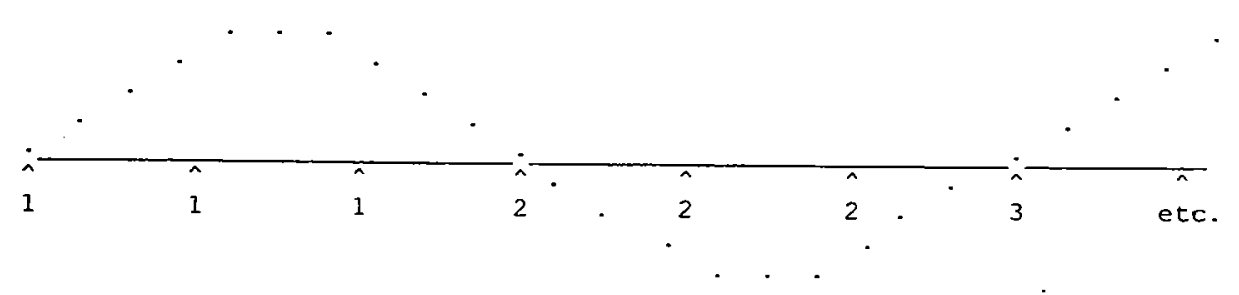

In addition, each bit is sent both true and complemented, and each code sequence is sent twice. That's a lot of bit redundancy, and just barely enough to make it past the noise on the line, depending on actual conditions.

A single normal command takes eleven cycles of the AC line to finish. All legal commands must first start with the header 1110 , a unique code as described below. The header bits take two cycles at one bit per half cycle. The next four cycles are the four-bit House Code, but it takes eight bits total because each bit is sent true then complemented. This is similar to biphase encoding, as the bit value changes state half-way through the transmission, and improves transmission reliability. The last five AC cycles are the Unit / Function Code, a five bit code that takes ten bits (again, true then complemented). For any codes except the DIM, BRIGHT and the data following the EXTENDED DATA function, there's a mandatory three cycle pause before sending another command DIM and BRIGHT don't necessarily need a pause, and the data after the EXTENDED DATA command absolutely MUST follow immediately until all bytes have been sent. The EXTENDED DATA code is handy, as any number of eight-bit bytes may follow. The data bytes must follow the true/complement rule, so will take eight cycles per byte, with no pause between bytes until complete. The only legal sequence that doesn't conform to the true/complement rule are the start bits 1110 that lead the whole thing off, likely because the modules need some way to tell when it's OK to start listening again.

A full transmission containing everything looks like this (see the end of this section for the actual command codes):
I 1110
H8 /H8
4 / 4 H2 /H2 Hl / H
D8 /D8
$D 4 / D 4$ D2 /D2 D1/DI $F / F$
(start)
(House code)
(Unit/Eunction code) 
So, to turn on Unit 12 of House code $A$, send the following:

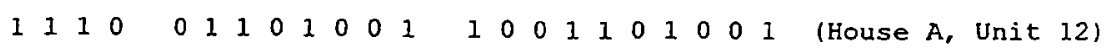

then wait at least three full $\mathrm{AC}$ cycles and send it again, then wait three and send:

$\begin{array}{lllllllllllllllllllllllll}1 & 1 & 1 & 0 & 0 & 1 & 1 & 0 & 1 & 0 & 0 & 1 & 0 & 1 & 0 & 1 & 1 & 0 & 0 & 1 & 1 & 0 & \text { (House } A, \text { Function } O N \text { ) }\end{array}$

again wait three cycles and send it the last time. Total transmission would have been 264 discrete bits (don't forget the 3-phase) and would take 53 cycles of the AC line, or about .883 seconds.

It's perfectly allowable to stack the Unit or Function codes together, so sending Unit 2 Unit 3 Unit 12 ON (separated by 3 cycles minimum) will turn on all 3 units. Stacking ON and OFF codes is annoying and flashes the lights quickly (roughly $4 \mathrm{~Hz}$ ).

\section{X10 COMMAND CODES}

\begin{tabular}{lcccc}
\multicolumn{5}{c}{ House Codes } \\
& H8 & H4 & H2 & H1 \\
A & 0 & 1 & 1 & 0 \\
B & 1 & 1 & 1 & 0 \\
C & 0 & 0 & 1 & 0 \\
D & 1 & 0 & 1 & 0 \\
E & 0 & 0 & 0 & 1 \\
F & 1 & 0 & 0 & 1 \\
G & 0 & 1 & 0 & 1 \\
H & 1 & 1 & 0 & 1 \\
I & 0 & 1 & 1 & 1 \\
J & 1 & 1 & 1 & 1 \\
K & 0 & 0 & 1 & 1 \\
L & 1 & 0 & 1 & 1 \\
M & 0 & 0 & 0 & 0 \\
N & 1 & 0 & 0 & 0 \\
O & 0 & 1 & 0 & 0 \\
P & 1 & 1 & 0 & 0
\end{tabular}

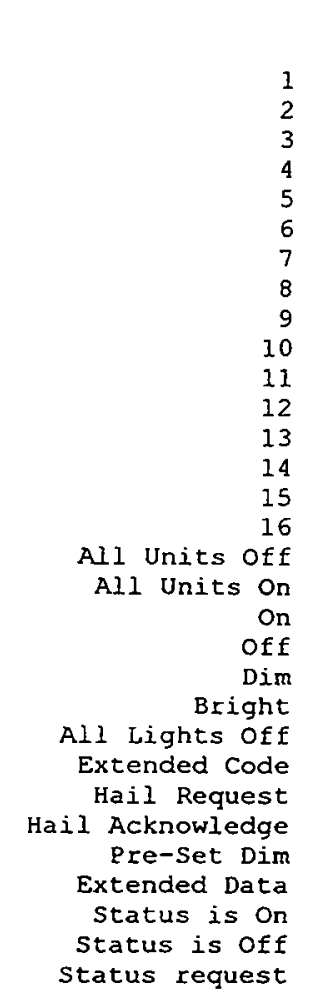

Unit/Function Codes

D8 D4 D2 D1 F

Note 1

Note 2

Note 3

Note 4 


\section{Computer Serial Port Interface Kit for X10}

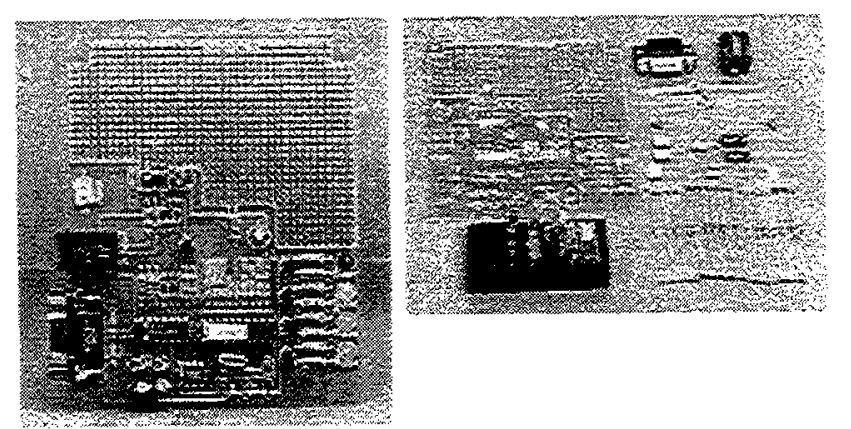

Translates The Complex Timing Critical TW523 Code Into Buffered ASCII

$\square$ Space provided for your own experimental circuitry

$\square$ New enhanced features!

Write your own X10 control program or develop your own X10 compatible product. It handles the complex timing of the X10 signals that are sent and received by the TW523 module and translates it into buffered ASCII code. Reading X10 activity or sending an X10 command becomes as simple as reading and writing ASCII codes to the serial port. You can use virtually any programming language that provides access to the serial port to send and read X10 signals. Space is provided on the circuit board for your own experimental circuitry. This kit is a great way to learn how to develop X10 compatible hardware. The latest version supports 50 and $60 \mathrm{~Hz}$ (for foreign usage), smoother dim/bright, automatic collision detection and retransmission, statistics counters and 32 byte FIFO buffer. A TW523 module, a RJ11 cable, and a serial cable and 12VDC power supply (not included) are required to complete the system. Kit requires assembly. Full instructions, sample source code, and a control program is provided.

HAS-1150 X10 Serial Port Interface Kit $\$ 69.95$

HAS-1152 X10 Serial Port Interface Assembled $\$ 139.95$

HAS-1155 DB9 Serial Cable + RJ11 Cable for Interface $\$ 9.95$

HAS-1135 X10 2 Way Interface Module (TW523) \$22.95

HAS-7590 12VDC 500mA Power Supply $\$ 7.95$

To order these items, enter quantities in the boxes above, and click "Add Item(s)" below.

Shopping Basket - 
Appendix 3, C: X-10 two-way interface module

\title{
X10 Powerhouse ${ }^{\mathrm{IM}}$ (TW523) Two Way Interface Module
}

\section{Develop, Your Own X10 Compatible Product or Software!}

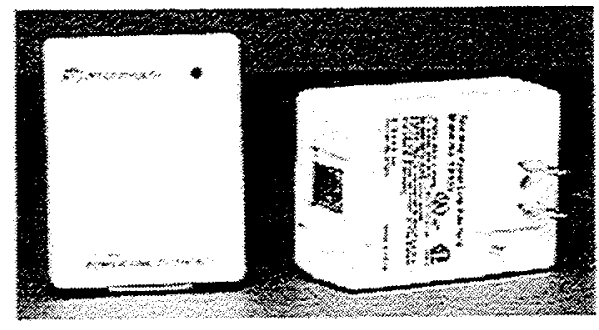

\author{
Send and Receive X10 Signals \\ $\square$ Develop your own X10 compatible products for sale without \\ the cost of UL approval
}

communication with your computer or from any other electronic device, you can develop and market your own software and/or hardware for use with X10 compatible systems without having to develop your own X10 communications hardware, or having to go through costly UL approval. This module is optically isolated and UL approved. The timing critical nature of communication with this device requires low level hardware programming experience. It may also require dedicated microprocessor time. It is not recommended for casual programmers. Documentation not included. Request HAS-1136 if instructions are required.

Our price: $\$ \mathbf{2 2 . 9 5 ,} 5$ or more $\$ \mathbf{1 8 . 9 9}$

\section{Now Available to Foreign Markets !}

For those with $220 / 240 \mathrm{~V}$ systems either $50 \mathrm{~Hz}$ or $60 \mathrm{~Hz}$, a new version of the TW523 is now available! It's the same unit as the TW523 with some modifications done to suit your needs.

Our price: $\$ 59.95$

\section{X10 Powerhouse ${ }^{\mathrm{Tm}}$ (PL513) One Way (Send Only) Interface Module}

For X10 Send Only Applications 
University of California, San Diego

SIO Library 0175C

9500 Gilman Drive

La Jolla, CA 92093-0175

Hancock Library of Biology \& Oceanography

Alan Hancock Laboratory

University of Southern California

University Park

Los Angeles, CA 90089-0371

Gifts \& Exchanges

Library

Bedford Institute of Oceanography

P.O. Box 1006

Dartmouth, NS, B2Y 4A2, CANADA

NOAA/EDIS Miami Library Center

4301 Rickenbacker Causeway

Miami, FL 33149

Research Library

U.S. Army Corps of Engineers

Waterways Experiment Station

3909 Halls Ferry Road

Vicksburg, MS 39180-6199

Institute of Geophysics

University of Hawaii

Library Room 252

2525 Correa Road

Honolulu, HI 96822

Marine Resources Information Center

Building E38-320

MIT

Cambridge, MA 02139

Library

Lamont-Doherty Geological Observatory

Columbia University

Palisades, NY z10964

Library

Serials Department

Oregon State University

Corvallis, OR 97331

Pell Marine Science Library

University of Rhode Island

Narragansett Bay Campus

Narragansett, RI 02882
Working Collection

Texas A\&M University

Dept. of Oceanography

College Station, TX 77843

Fisheries-Oceanography Library 151 Oceanography Teaching Bldg.

University of Washington

Seattle, WA 98195

Library

R.S.M.A.S.

University of Miami

4600 Rickenbacker Causeway

Miami, FL 33149

Maury Oceanographic Library

Naval Oceanographic Office

Building 1003 South

1002 Balch Blvd.

Stennis Space Center, MS, 39522-5001

Library

Institute of Ocean Sciences

P.O. Box 6000

Sidney, B.C. V8L 4B2

CANADA

National Oceanographic Library

Southampton Oceanography Centre

European Way

Southampton SO14 3ZH

UK

The Librarian

CSIRO Marine Laboratories

G.P.O. Box 1538

Hobart, Tasmania

AUSTRALIA 7001

Library

Proudman Oceanographic Laboratory

Bidston Observatory

Birkenhead

Merseyside L43 7 RA

UNITED KINGDOM

IFREMER

Centre de Brest

Service Documentation - Publications

BP 7029280 PLOUZANE

FRANCE 


\begin{tabular}{|c|c|c|c|}
\hline $\begin{array}{l}\text { REPORT DOCUMENTATION } \\
\text { PAGE }\end{array}$ & 1. REPORT NO. WHOI-97-14 & $\begin{array}{l}\text { UOP-97-04 } \\
\end{array}$ & 3. Recipient's Accession No. \\
\hline \multirow{2}{*}{\multicolumn{3}{|c|}{$\begin{array}{l}\text { 4. Title and Subtitle } \\
\text { Feasibility of Wireless Data Transmission on Ships }\end{array}$}} & $\begin{array}{l}\text { 5. Report Date } \\
\text { October } 1997\end{array}$ \\
\hline & & & 6. \\
\hline \multicolumn{3}{|l|}{ 7. Author(s) David S. Hosom } & $\begin{array}{l}\text { 8. Performing Organization Rept. No. } \\
\text { WHOI-97-14 }\end{array}$ \\
\hline \multirow{2}{*}{\multicolumn{3}{|c|}{$\begin{array}{l}\text { 9. Performing Organization Name and Address } \\
\text { Woods Hole Oceanographic Institution } \\
\text { Woods Hole, Massachusetts } 02543\end{array}$}} & 10. Project/TaskWork Unit No. \\
\hline & & & $\begin{array}{l}\text { 11. Contract(C) or Grant(G) No. } \\
\text { (C) OCE96-32461 } \\
\text { (G) }\end{array}$ \\
\hline \multirow{2}{*}{\multicolumn{2}{|c|}{$\begin{array}{l}\text { 12. Sponsoring Organization Name and Address } \\
\text { National Science Foundation }\end{array}$}} & \multirow[t]{2}{*}{-} & $\begin{array}{l}\text { 13. Type of Report \& Period Covered } \\
\text { Technical Report }\end{array}$ \\
\hline & & & 14. \\
\hline
\end{tabular}

15. Supplementary Notes

This report should be cited as: Woods Hole Oceanog. Inst. Tech. Rept., WHOI-97-14.

16. Abstract (Limit: 200 words)

This report will present the results of an investigation into the feasibility of several modes of wireless data transmission including: (1) radio frequency modems, (2) acoustic modems (using the ship's steel hull for a path with a "HullPhone"), (3) power line systems, such as X-10 units, and (4) possible power line utilization of telephone modems.

There is a need for wireless data transmission on both Voluntary Observing Ships (VOS) and research ships for short-term installations. The availability of cables from remote areas on these ships is usually not good, and restrictions on installing cables prevent some useful measurements from being made. A case in point is the real time availability of measurements of sea surface temperature (SST) from VOS by sensors mounted inside the hull. Instruments for measuring SST are installed in sealed compartments that are near the waterline of the ship and often four decks below the main deck. Other applications include transmission of data from automated XBT launchers located on the aft deck to the science area and transmission of data from a cluster of meteorological instruments located at the bow of the ship to the bridge for interface to Service Argos or Inmarsat satellite links.

Surveys of existing equipment have been made. Typical equipment has been purchased and tested in a ship environment, including the "HullPhone." The results of these tests are presented. Suggestions for system configurations to meet the applications noted above are made with note of the product development required.

17. Document Analysis a. Descriptors

wireless shipboard data

acoustic ship model

HullPhone data

b. Identifiers/Open-Ended Terms

c. COSATI Field/Group

18. Availability Statement

Approved for public release; distribution unlimited.

\begin{tabular}{|l|l|}
$\begin{array}{l}\text { 19. Security Class (This Report) } \\
\text { UNCLASSIFIED }\end{array}$ & $\begin{array}{c}\text { 21. No. of Pages } \\
37\end{array}$ \\
\hline 20. Security Class (This Page) & 22. Price \\
\hline & $\begin{array}{l}\text { OPTIONAL FORM 272 (4-77) } \\
\text { (Formerly NTIS-35) } \\
\text { Department of Commerce }\end{array}$ \\
\hline
\end{tabular}

